\title{
REGULAÇÃO PRUDENCIAL NO PÓS-CRISE: O DEBATE CONTEMPORÂNEO
}

\author{
Dissertação de Mestrado \\ Orientador: Professor Dr. Jean-Paul Veiga da Rocha
}

UNIVERSIDADE DE SÃO PAULO

FACULDADE DE DIREITO

São Paulo-SP

2019 


\section{REGULAÇÃO PRUDENCIAL NO PÓS-CRISE: O DEBATE CONTEMPORÂNEO}

Dissertação de Mestrado, apresentada a Banca Examinadora do Programa de Pós-Graduação em Direito, da Faculdade de Direito da Universidade de São Paulo, na área de concentração em Teoria Geral e Filosofia do Direito, sob a orientação do Prof. Dr. JeanPaul Veiga da Rocha.

UNIVERSIDADE DE SÃO PAULO

FACULDADE DE DIREITO

São Paulo-SP 
RAFAEL EDELMANN DE OLIVEIRA BAPTISTA

\section{REGULAÇÃO PRUDENCIAL NO PÓS-CRISE: O DEBATE CONTEMPORÂNEO}

Dissertação de Mestrado, apresentada a Banca Examinadora do Programa de Pós-Graduação em Direito, da Faculdade de Direito da Universidade de São Paulo, na área de concentração em Teoria Geral e Filosofia do Direito, sob a orientação do Prof. Dr. JeanPaul Veiga da Rocha.

Aprovada em:

Banca examinadora:

Prof.:

Julgamento:

Prof.:

Julgamento:

Prof.:

Julgamento:
Instituição:

Assinatura:

Instituição:

Assinatura:

Instituição:

Assinatura: 


\section{AGRADECIMENTOS}

A conclusão desta pesquisa representa uma vitória, que definitivamente não atingi sem a ajuda de várias pessoas que me apoiaram e estiveram comigo ao longo desse caminho.

Primeiramente agradeço ao meu orientador, professor Jean-Paul Veiga da Rocha, com quem descobri os caminhos da seriedade acadêmica e do pensamento crítico e combativo como elementos fundamentais na construção de uma sociedade democrática. Agradeço a ele a oportunidade de desde 2013 colaborar com a disciplina de Sociologia Jurídica, ministrada para a graduação da Faculdade de Direito da USP, bem como ao período em que trabalhamos no GARMR - Grupo de Análise, Regulação Moeda e Risco. Mas principalmente, agradeço-o a todos os cafés, almoços e corridas de taxi para lugares comuns no curso dos quais muitas ideias foram debatidas e lapidadas.

Agradeço a Rafael Zanatta e Pedro Salomon, com quem já em 2011 passei a me interessar e perseguir temas relacionados à relação entre direito, economia e sociedade.

O desenho final deste projeto de pesquisa apenas tomou forma após a banca de qualificação, pelo que agradeço imensamente aos comentários pertinentes e instigantes da professora Mariana Pargendler e do professor Diogo Coutinho, além do professor Jean-Paul, que muito contribuíram para o resultado final deste trabalho.

Também, pelo desenho final deste projeto tenho muito a agradecer a Guilherme Meireles, amigo com quem sempre posso contar, e com quem debati os rumos de minha pesquisa em praticamente todos os seus momentos, sempre com olhares críticos, atentos e pertinentes. Ainda, ao resultado deste projeto devo agradecer ao Victor Doering "Deeds", Flávio Marques Prol e Francisco Britto Cruz, amigos e colegas de orientação, com quem pude compartilhar minhas ideias e inquietudes acadêmicas.

Todo o percurso que envolve esse projeto é de especial importância para mim, principalmente ao longo do processo seletivo em 2015 até meados de 2016, 
pois representa uma fase de muitas superações e vitórias de caráter também pessoal, e não somente acadêmico.

A esse período agradeço novamente ao professor Jean-Paul, e também aos colegas com quem trabalhei no Núcleo de Estado e Sociedade Civil do Centro de Pesquisa Jurídica Aplicada da Faculdade de Direito da FGV São Paulo, Leonel Cesarino Pessoa, Aline Gonçalves de Souza, Bianca dos Santos Wacks, Eduardo Panuzzio e Mariana Vilella. A esse período agradeço imensamente também a Rodolfo Mazzini, Filipe Gomes, Amália Batocchio, Marianne Reis e Luisa Rossit, bem como a Daniel e Diego Carrion, Yasmin Verdini, Wilson Tayar, Vinícius Papa e Renan Saglia, além do Caio Sartorelo e da Fernanda Gomes, Felipe Dias e Patrícia Bueno, grandes amigos, todos eles para a vida, com quem pude contar e que estiveram comigo nos momentos mais difíceis.

Grande parte desse projeto foi desenvolvido em conjunto com a advocacia, ao que agradeço a Pedro Guilherme de Souza, com quem passei a me aproximar do sistema financeiro nacional, elemento relevante para o desenho final deste projeto. Bem como, aos atuais colegas de prática, com quem em pouco tempo já tive várias e instigantes discussões jurídicas e de carreira, Cássio Gama Amaral, Camila Calais, Luciana Prado, Marcelo Mansur, Thomaz Kastrup, Beatriz Perez, Paula Calheiros da Costa, Thales Costa, Bernardo Campos, André Hermont, Mary Hamasaki, Anália Brum, Allan Chammas, Juliana Strohl, Beatriz Perez, Nathália Cassone, Flávia Hammerle, Ana Clara, Anthony Novaes, Lucas Marina, Laura Fillietaz, Amanda Coatti, Rodrigo Breda, Fábio Gobara, Úrsula Goulart e Karen Schiavon; bem como Hugo Trapp e Gabriel Figuinha.

Por todos esses momentos, e por muitos mais, agradeço à minha família. A meus pais, Eliane e Jeferson, à minha vó Neusa, meu irmão Felipe e minha cunhada Natália. Eles tiveram a força para me aguentar falando várias e várias vezes sobre o mestrado, bem como me apoiaram em todas as ausências que a realização deste projeto causou. Por fim, agradeço à Letícia Cardoso, minha companheira para a vida, com quem divido os meus dias e mais do que ninguém me escutou falando sobre esse mestrado e sentiu as ausências que ele causou.

A todos posso apenas dizer OBRIGADO! E que lhes devo um grande e efusivo abraço, além da minha gratidão! 


\section{RESUMO}

A presente dissertação tem por escopo a análise, linha a linha, do debate teórico sobre regulação prudencial, surgido por consequência da crise financeira de 2008, travado entre Anat Admati e Martin Hellwig, de um lado, e seus interlocutores. Com relação aos interlocutores, o presente trabalho se focará em três deles, notadamente, Gary Gorton, Gunther Teubner e John Armour, este último em conjunto com outros autores. A noção de regulação prudencial, de modo geral ao sistema financeiro, diz respeito à determinação de requisitos de capital (regras de financiamento, alavancagem etc.) e liquidez (estabelecimento de reservas, principalmente), com o objetivo de promover a estabilidade institucional, no plano micro, e a solidez e estabilidade sistêmica no plano macro. Diante da análise das controvérsias teóricas emergentes no debate em questão, conclui-se no presente trabalho que: (i) deve-se entender a crise financeira de 2008 não apenas como o choque inicial ocorrido no mercado imobiliário norteamericano, devendo-se considerar também os mecanismos institucionais que permitiram sua disseminação a nível global; (ii) há fortes argumentos no sentido de que o maior custo de financiamento com capital em relação ao débito é uma realidade institucional contingente, passível de modificação diante de reformas estruturais do sistema financeiro e da regulação prudencial; (iii) conclusão final sobre a aplicabilidade do teorema de Modigliani-Miller às instituições bancárias depende de desenvolvimentos teóricos e empíricos adicionais; (iv) a política do 'plain money', ou seja, o estabelecimento de $100 \%$ de reservas contra os depósitos à vista tomados por bancos comerciais, parte de diagnóstico que ignora a eclosão da crise de $2008 \mathrm{em}$ bancos de investimento, como o Lehman Brothers, estruturalmente diversos daqueles primeiros.

Palavras-chave: "regulação prudencial"; "política prudencial”; "estabilidade sistêmica"; "crise de 2008"; "crises financeiras"; "Anat Admati"; "Martin Hellwig"; "teorema de Modigliani-Miller"; "plain money”. 


\begin{abstract}
This dissertation aims to analyze line by line the theoretical debate about prudential regulation that emerged because of the 2008 financial crisis, between Anat Admati and Martin Hellwig, and its interlocutors. The present work will focus mainly on three of their interlocutors, namely, Gary Gorton, Gunther Teubner and John Armour, this last one alongside other authors. In a general way to the financial system, prudential regulation regards the determination of capital (financing rules, leverage etc.) and liquidity (constitution of reserves, mainly), with the objective to promote institutional stability at the micro level, and systemic stability and robustness at the macro level. Following the analysis of this debate, we conclude in the present work that: (i) one must understand the financial crisis of 2008 as not just the initial chock that happened in the American home credit market, being important to also consider the institutional mechanisms that allowed its dissemination throughout the world; (ii) there are strong arguments in the sense that the larger costs of capital financing in comparison with debt financing are part of a contingent institutional reality, possible to change in case of structural reforms of the financial system and prudential regulation; (iii) the final conclusion on the applicability of the Modigliani-Miller theorem to banks depends on further theoretical and empirical developments; (iv) the 'plain money' policy, which requires the constitution of $100 \%$ in reserves against demand deposits in commercial banks, depends on a diagnosis that ignores that the 2008 crisis broke out in investment banks such as Lehman Brothers, structurally diverse from those first ones.
\end{abstract}

Key-words: "prudential regulation"; "prudential policy"; "financial stability"; "2008 crisis"; "financial crisis"; "Anat Admati"; "Martin Hellwig"; "Modigliani-Miller theorem"; "plain money". 


\section{LISTA DE SIGLAS E ABREVIATURAS}

A\&H Anat Admati e Martin Hellwig, quando referidos em conjunto

$\mathrm{ABCP}$ Asset Backed Commercial Papers

$\mathrm{ABX}$

Índice derivativo atrelado à dívida imobiliária norte americana

AIG American International Group

ARM

Alternate Rate Mortgages

BIS

Bank for International Settlements

CAMELS Método de avaliação da higidez institucional de instituições bancárias

CBSB Comitê da Basileia para supervisão Bancária

CCAR Comprehensive Capital Analysis and Review

CDO Collateralized Debt Obligation

CDS Credit Default Swap

CET1 Common Equity Tier 1

CRD Capital Requirements Directive

CRD IV Capital Requirements Directive IV

FCIC Financial Crisis Inquiry Comission

FDIC Federal Deposit Insurance Comission

FED Federal Reserve, banco central dos Estados Unidos

FGC Fundo Garantidor do Crédito

FSB Financial Stability Board

G20 Grupo das vinte maiores economias mundiais

IAIS International Association of Insurance Supervisors

IFSI Instituições Financeiras Sisteminamente Importantes

IOSCO International Organization of Securities Comissions

M\&M Franco Modigliani e Merton Miller, quando referidos em conjunto

RWA Risk Weighted Assets

S\&L Associação de Savings and Loans, espécia de instituição financeira

SIFI Sistemicaly Important Financial Institutions

USD Dólares norte-americanos 
SUMÁRIO

1 INTRODUÇÃO .13

1.1 REGULAÇão PRUDENCIAL, POLÍtICA PRUDENCIAL E SUPERVISÃo

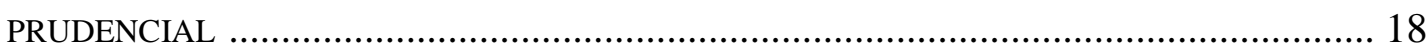

1.2 A REGULAÇÃO PRUDENCIAL NO PRÉ-CRISE ...............................................23

1.2.1 Dois momentos: o pré e o pós-crise de 2008 ………………………….....23

1.2.2 O debate prudencial no pré-crise: centralidade dos aspectos microprudenciais

1.2.3 Indicadores de monitoramento da higidez institucional ..........................25

1.2.4 Primeiras considerações acerca de uma regulação macro-prudencial...29 1.3 PROCESSO POLÍTICO DE REFORMA DA REGULAÇão PRUDENCIAL NO PÓSCRISE 30

2 DIAGNÓSTICOS DA CRISE DE 2008 ……………………………………........

2.1 TEORIAS DA CRISE: PERSPECTIVA DE A\&H EM CONTEXTO ......................37

2.2 CAUSAS DA CRISE DE 2008: DEBATE ENTRE A\&H E GARY GORTON ......42

2.2.1 Narrativa da liquidez de Gary Gorton ...............................................43

2.2.2 Narrativa da solvência de A\&H.......................................................50

2.2.3 Dez críticas de A\&H à narrativa de Gary Gorton ...............................59

3 CAPITAL

CUSTO DE CAPITAL E CUSTO DE DÉBITO ……......................................... 75

3.2 TRÊS DIFICULDADES PARA O AUMENTO DOS REQUISITOS DE CAPITAL......81

3.3 O TEOREMA DE MODIGLIANI-MiLleR E SUA (IN)APLICABILIDADE ÀS INSTITUIÇÕES BANCÁRIAS

4 LIQUIDEZ: O ‘PLAIN MONEY’ DE VOLTA À MESA DE DEBATES ….....107

5 PROPOSTAS DE REFORMA DA REgUlaÇÃo PRUDENCIAL NO PÓSCRISE 
5.1 SOLUÇÃO TRADICIONAL OU INOVAÇÃO INSTITUCIONAL?

117

5.2 Rigidez DAS ESTRUTURAS DE CAPITAL OU EXTENSÃO DO SEGURO DE CRÉDITO PARA O SETOR DE SHADOW BANKING?......................................................119

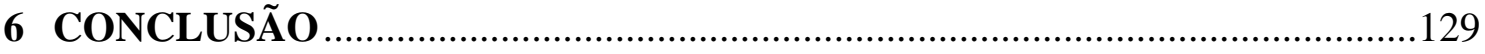

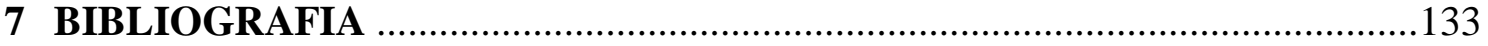


Now, everyone has the same question: how much worse can this get? This lack of confidence is self-fulfilling and endangers other financial institutions. These are companies that refinance themselves in the capital markets every day. They depend on the confidence of lenders. But, if that disappears, their solvency is threatened. This is where we are now.

$[\ldots]$

This will come to be seen as the greatest regulatory failure in modern history. The degree of leverage that these institutions took on is indefensible. The average large securities firm was leveraged 27 to one in mid-2007. They were not regulated by any prudential supervisor. In effect, they regulated themselves. The lack of transparency was stunning. Many big lenders did not disclose off-balance-sheet risks. In some cases, they did not understand these risks themselves. More fundamentally, we allowed a second, huge financial system to develop outside the normal banking network. It consisted of investment banks, mortgage finance companies and the like. It was unregulated, not transparent and way too leveraged. But with nine separate and mostly ineffective financial regulators, these risks were ignored. That is, until this second system crashed.

(Altman, Roger. Financial Times, 17 de Setembro de 2008)

\section{When She Talks, Banks Shudder}

$[\ldots]$

Bankers are nearly unanimous on the subject of Anat $R$. Admati, the Stanford finance professor and persistent industry gadfly: Her ideas are wildly impractical, bad for the American economy and not to be taken seriously.

$[\ldots]$

Ms. Admati's simple message is that the government is overlooking the best way to strengthen the financial system. Regulators, she says, need to worry less about what banks do with their money, and more about where the money comes from.

(Applebaum, Binyamin. New York Times, 9 de Agosto de 2014) 


\section{INTRODUÇÃO}

O presente trabalho se constitui em estudo monográfico que tem por escopo a análise, linha a linha, do debate teórico sobre regulação prudencial, surgido por consequência da crise de 2008, travado entre Anat Admati e Martin Hellwig ("A\&H" ou "Admati e Hellwig"), de um lado, e seus interlocutores. Com relação aos interlocutores, o presente trabalho se focará em três deles, notadamente, Gary Gorton, Gunther Teubner e John Armour, este último em conjunto com outros autores ${ }^{1}$.

Gary Gorton é um dos principais teóricos econômicos no tema de crises financeiras, tendo produzido trabalhos relevantes sobre as crises e corridas bancárias do século XIX nos Estados Unidos, culminando com a crise de 1929, e posteriormente sobre a crise de 2008 e reforma da regulação prudencial no pós-crise ${ }^{2}$. O argumento de A\&H sobre regulação prudencial no pós-crise de 2008 é diverso, e para que se sustente, depende da crítica e superação ao argumento de Gary Gorton. Armour et alii (2016), por sua vez, desenvolvem argumento posterior ao de $\mathrm{A} \& \mathrm{H}$, e, também, dependem da crítica e superação destes últimos. Desenvolve-se, neste sentido, um debate teórico explícito entre esses autores. Gunther Teubner, por sua vez, não é um interlocutor explícito. Entretanto, Teubner desenvolve diagnóstico acerca das causas da crise de 2008, e propõe reformas estruturais do sistema financeiro direcionadas à regulação prudencial, que são incompatíveis teoricamente com o trabalho de A\&H. Desta forma, independentemente das diferenças de tradição teórica entre Teubner e A\&H, é possível e relevante que se desenvolva análise do diálogo crítico formado a partir do trabalho desses autores.

Com relação a esses três interlocutores, a análise linha a linha que será aqui desenvolvida será direcionada à compreensão de seus argumentos, identificação dos pontos fortes e fracos, e abertura dos caminhos para sua complementação ou superação.

Admati e Hellwig têm desenvolvido, individualmente e em conjunto, desde a crise de 2008, um intenso trabalho sobre regulação prudencial, profundamente crítico acerca

1 Trata-se de trabalho coletivo no qual John Armour consta como primeiro autor, mas que é também assinado por Dan Awrey, Paul Davies, Luca Enriques, Jeffrey Gordon, Colin Mayer e Jennifer Payne, intitulado "Ptinciples of Finalcial Regulation" (2016). A identificação da autoria será restrita a Armour no curso deste trabalho, por motivos de organização.

${ }^{2}$ No campo das teorias de crises financeiras, corridas bancárias e regulação de liquidez, deve-se considerar também Douglas Diamond $(1983 ; 1984 ; 1991 ; 2001 ; 2011)$ que, apesar de possivelmente mais relevante que Gorton, não trava debate direto com A\&H. Nesse sentido, Diamond não se encontra entre os autores analisados no presente trabalho. 
da forma como a regulação se estrutura, bem como acerca das relações políticas entre instituições financeiras, governos e órgãos reguladores, além de proporem mudanças radicais no escopo e objetivos da regulação prudencial.

Anat Admati é uma economista israelense radicada nos Estados Unidos, onde é professora de finanças e economia na Universidade de Stanford, e desde 2010 vem se engajando profundamente no debate acadêmico acerca da regulação prudencial ${ }^{3}$.

Martin Hellwig, alemão e também economista, atua academicamente desde 1971, tendo passagens por Heidelberg, M.I.T., Stanford e Harvard, e hoje é Diretor do Instituto Max Plank para Pesquisa sobre Bens Coletivos, em Bonn, na Alemanha. Vem desenvolvendo intensamente seu trabalho sobre regulação prudencial e estabilidade sistêmica desde 2008, sendo esse já um dos grandes temas de sua produção acadêmica, e, ao lado de Admati, adota uma postura profundamente crítica acerca do estado atual de coisas no sistema financeiro global ${ }^{4}$.

Admati e Hellwig, além de suas produções individuais, têm trabalhos substanciais em conjunto publicados no campo da regulação prudencial, dentre os quais o que se pode considerar já uma das principais peças produzidas sobre esse tema após e por causa da crise de 2008, The Bankers' New Clothes. Fortemente crítico, o livro desenvolve uma análise profunda de todos os principais temas e problemas que emergiram no campo da regulação prudencial com a crise. Acompanhando o livro, ambos os autores têm publicado artigos científicos e matérias em jornais, além de participado intensamente do debate público $^{5}$, reforçando, aprofundando, desenvolvendo e disseminando as ideias que sintetizam no livro, peça central da produção desses autores no tema.

A partir de suas ideias, fortemente críticas, Admati e Hellwig se engajam no debate travado tanto com outros acadêmicos, quanto com atores políticos, intelectuais orgânicos do sistema financeiro, empresários do setor e o público em geral, de tal modo que se pode considerar esses autores como os pontos pivotais do debate acadêmico - e especialmente do debate acadêmico crítico - sobre regulação prudencial que emerge por consequência da crise de 2008.

$3<$ https://www.gsb.stanford.edu/faculty-research/faculty/anat-r-admati $>$, acesso: 26.07.2018.

$4<$ https://www.coll.mpg.de/sites/www/files/team/files/CVengl_1.pdf $>$, acesso: 26.07.2018.

${ }^{5}$ Nesse ponto, especialmente Admati tem sido intensamente ativa, ministrando palestras como no TEDxStanford. <https://youtu.be/s_I4vx7gHPQ>, , acesso: 06.01.2017. 
A crítica desenvolvida por Admati e Hellwig tem duas perspectivas principais. De um lado, trata do conjunto dos autores acadêmicos, atores políticos e orgânicos do sistema financeiro que produzem conteúdo e participam do debate público e da definição das políticas públicas relacionadas à regulação prudencial e à estabilidade sistêmica. Do outro lado, trata do conteúdo do pensamento produzido sobre regulação prudencial, e nesse contexto é que Admati e Hellwig desenvolvem sua análise substantiva acerca do tema. De todo modo, a partir do pensamento de Admati e Hellwig é possível tanto se desenvolver uma metacrítica do debate prudencial, focada num olhar acerca dos autores e produtores desse conteúdo, quanto uma análise substantiva e interna do debate.

Além dos interlocutores analisados no presente trabalho, é possível que existam outros, principalmente quanto se diz respeito ao estabelecimento de debates implícitos entre A\&H e outros autores. Para fins do presente trabalho, Gary Gorton é o interlocutor principal, estabelece diálogo explícito com $\mathrm{A} \& \mathrm{H}$, de tal modo que representam contraponto no debate público contemporâneo sobre regulação prudencial. A crítica de Armour et alii também é explícita, e sua resposta é fundamental para a sustentação de determinados argumentos de $\mathrm{A} \& \mathrm{H} . \mathrm{A} \& \mathrm{H}$, entretanto, até onde se tem conhecimento, não publicaram resposta às críticas de Armour et alii. Também, até onde se tem conhecimento, Gary Gorton não publicou réplica às críticas de $\mathrm{A} \& \mathrm{H}$.

No curso dos debates analisados, alguns tópicos da regulação prudencial ganham relevo em detrimento de outros. Seja porque tais autores concordam com determinados pontos de diagnóstico ou de proposta regulatória, seja porque esses tópicos ainda não foram levantados no debate acadêmico. Desta forma, alguns elementos e tópicos típicos da regulação prudencial não serão aprofundados no presente trabalho. Notadamente, dois tópicos não serão analisados. O primeiro deles diz respeito à oposição entre regulação (micro) prudencial e macro prudencial. A divergência entre regulação micro e macro prudencial é central para o desenvolvimento teórico desse campo regulatório, principalmente a partir da crise de 2008. Entretanto, trata-se de um desenvolvimento teórico recebido de forma consensual na comunidade acadêmica, a partir de desenvolvimentos ocorridos na década de 1990, movimento do qual o próprio Martin Hellwig participa (Hellwig, 1995), e que não se tornou objeto da disputa teórica sobre o tema surgida a partir da crise de 2008. Não obstante, o processo de formação teórica da regulação macro-prudencial no pré-crise, e sua disseminação após a crise de 2008, será brevemente analisado ainda na introdução deste trabalho. O segundo desses tópicos diz respeito à ponderação de ativos pelo risco, ou, do 
inglês risk wieghted assets ("RWA"). O RWA é uma técnica regulatória desenvolvida desde as primeiras convenções da Basileia, através do que diferentes tipos de ativos possuem diferentes 'pesos', ou fatores, que devem ser aplicados a eles para fins de determinação do capital. Por exemplo, um título público pode ter fator de 0 , de tal modo que um banco pode adquirir o quanto quiser que isso nunca alterará a contrapartida que deve ter em capital. Ao mesmo tempo, um título altamente arriscado pode ter fator próximo a 1, ou mesmo maior que 1, o que aumentará consideravelmente as contrapartidas que se deverá ter em capital para adequação da instituição financeira àquele risco. A\&H questionam a prática do RWA e propõe a sua extinção como técnica regulatória. Entretanto, não se identificou debate crítico relevante com relação a esse tema. Outros autores que abordam o problema do RWA, como é feito em Armour et alii (2016), desenvolvem críticas internas ao modelo, discutindo as melhores formas de ponderação dos ativos pelo risco e pressupondo a sua pertinência enquanto técnica regulatória.

No trabalho de Admati e Hellwig, especialmente no Bankers' New Clothes, desenvolve-se uma série de conceitos e tipos que podem ser utilizados para a análise e classificação do debate acerca da regulação prudencial, tanto aquele que já se desenvolvia antes, quanto o que se desenvolve por consequência da crise de 2008. Dentre tais conceitos, dois são especialmente relevantes para situá-los, bem como a seus interlocutores, no que se pode chamar de debate acadêmico acerca da regulação prudencial no pós-crise de 2008, ou, sucintamente, debate prudencial do pós-crise. A primeira distinção, trata da oposição entre pensadores "independentes" e "orgânicos". A segunda distinção, trata da necessidade, ou não, de se engajar no debate prudencial a partir de uma perspectiva econométrica e altamente matematizada, ou se é suficiente que esse engajamento se dê a partir de uma perspectiva política e normativa.

Admati e Hellwig se apresentam como autores que não guardam vínculos de interesse com o mercado financeiro e nem com a política, tendo posição de perspectiva privilegiada para a crítica que desenvolvem em seu trabalho. Essa postura não é geral a todo o pensamento sobre regulação prudencial que se desenvolve a partir da crise de 2008, e esse é um dos principais pontos da crítica desenvolvida pelos autores ${ }^{6}$. Segundo Admati e

${ }^{6}$ Assim se sugere em excertos como o seguinte: "The Bankers' New Clothes focuses mainly on bankers and lobbyists making false or misleading claims and on the politicians and regulators who listen to them and collaborate with them. Yet, flawed claims and willful blindness can also be found among academics 
Hellwig, parte considerável da produção acadêmica sobre o tema vem sendo dominada por argumentos falaciosos, construídos propositalmente para se adequarem aos interesses do sistema financeiro, ou melhor, mais especificamente, dos interesses de uma determinada classe de administradores de instituições financeiras que têm uma série de incentivos para pressionarem a política e as instituições regulatórias no sentido de permanecerem lenientes com relação à regulação prudencial (2013, pg. 71). Partindo dessa perspectiva, podemos analisar os demais autores participantes do debate prudencial a partir da chave "independentes", ou "orgânicos", para designarmos autores desvinculados ou vinculados a interesses do setor financeiro, respectivamente.

Outro ponto fortemente salientado por Admati e Hellwig se trata da necessidade ou não de se desenvolver um raciocínio econométrico acerca da regulação prudencial, fundamentado em matematizações densas nas quais se busca a determinação de taxas e proporções ótimas de cada um dos índices que compõe a análise de solvência das instituições financeiras. Há autores que se utilizam do raciocínio econométrico como elemento essencial ao desenvolvimento de se argumento (Diamond e Dybvig, 1983; Rubio e Carrasco-Gallego, 2014), o que entretanto não se trata de elemento essencial para o debate sobre regulação prudencial. Para esses autores, o papel da academia no debate sobre regulação prudencial é a identificação dos níveis ótimos de capital e reservas que devem ser adotadas pelas instituições financeiras de modo a se maximizar a eficiência alocativa dos recursos dessas instituições. Admati e Hellwig, todavia, não compartilham dessa visão, e são críticos dela ${ }^{7}$. Consideram os autores que a determinação a priori de índices de capital e reservas pressupõe uma harmonização das regras contábeis que determinam a mensuração desses índices, o que pode ser consideravelmente diferente a depender da jurisdição. A exemplo disso, considerase que uma mesma proporção de capital pode ter significados diferentes na Alemanha e nos Estados Unidos, diante das diferenças entre as regras e padrões contábeis vigentes em cada um desses países. Além das diferenças contábeis, Admati e Hellwig consideram que não faz

and in the media; they too participate in the continuing parade of bankers' new clothes. For example, the 2013 edition of a best-selling textbook, written by a prominent academic and former central banker, repeats fallacious statements that have been publicly debunked in our book and in earlier writings; these statements contradict basic lessons taught in required business school courses in finance." (Admati; Hellwig, 2013, p. xi)

7 "Since 2010, when we became more outspoken about the need for an ambitious reform of capital regulation, we have engaged in many discussions on the subject, yet we have never received a coherent answer to the question of why banks should not have equity levels between 20 and 30 percent of their total assets.56 (A caveat on providing specific ratios is that their meaning will depend on accounting conventions.)." (Admati; Hellwig, 2013, pp. 181-182). 
sentido a determinação a priori de requisitos ótimos de capital e reservas por conta das incertezas envolvidas nessas determinações ${ }^{8}$. Há uma série de fatores que podem influenciar as necessidades específicas em cada jurisdição e conjuntura econômica, bem como em cada instituição financeira, de tal modo que a determinação a priori de requisitos específicos de capital e reservas perde o sentido prático. Seguindo este raciocínio, a melhor forma de se pensar academicamente a regulação prudencial é por quantificadores bastante gerais como "muito", "pouco", "tudo" ou "nada".

Desta forma, pode se considerar aí também uma distinção significativa entre os autores engajados no debate prudencial, entre os que chamaremos de "eficientistas", ou seja, aqueles que defendem uma posição fundamentalmente econométrica e precisa para o papel da academia no debate prudencial, focada na determinação de índices ótimos de capital e reservas. Do outro lado, pode se considerar o conjunto de autores, como Admati e Hellwig, que adotam e defendem uma perspectiva mais geral, menos matematizada e mais política acerca do pensamento sobre regulação prudencial, aos quais chamaremos de "generalistas".

\subsection{Regulação PRUdencial, POlítica PRUdencial E SUPERVisão PRUDENCIAL}

O presente trabalho, também, além de adotar por fio condutor o trabalho de Admati e Hellwig, parte de uma definição específica acerca do conceito de regulação prudencial. Para tanto, é relevante que se distinga, em primeiro lugar, o escopo da regulação prudencial para, na sequência, diferenciar-se também a ideia de regulação para as ideias de política e supervisão prudenciais. Esses três elementos constituem o campo de debate político econômico que se pode chamar de propriamente "prudencial", e desta forma se interrelacionam e, por vezes, se sobrepõe. Todavia, tomado de forma ampla, o problema políticoecoômico da regulação prudencial é demasiadamente extenso para fins da presente dissertação, além de envolver exigências e temáticas que fogem ao escopo do presente trabalho.

Desta forma, pode-se num patamar mais amplo falar-se em "política prudencial", como sendo todo o conjunto de ações e movimentações práticas adotadas pelos agentes

8 "The attempt to fine-tune equity regulation is based on an illusion. Besides the problems of corruption by politics and manipulation by the banks, the risks themselves are changing all the time, and even the banks lack the information necessary to measure them properly.” (Admati; Hellwig, 2013, p. 186). 
relevantes numa determinada comunidade política com o fim de promover a estabilidade sistêmica do sistema financeiro daquela comunidade política. Esse conjunto de ações envolve a regulação que pode se considerar efetivamente prudencial, mas também envolve outros aspectos da regulação, como governança corporativa - a exemplo dos critérios de bônus e pagamento dos administradores financeiras, incentivos relevantes para a tomada, ou não, de riscos excessivos por essas instituições, e matéria amplamente debatida nas arenas políticas de reforma da regulação financeira que sucederam a crise de 2008 (Bentz, Mayntz, 2015; pg. 175; Quaglia, 2015; pg. 102, entre outros) -, falência e recuperação judicial de instituições financeiras, regulação de contratos financeiros etc. Além disso, a análise desse espectro do ambiente prudencial envolve também as considerações dos jogos de interesse concretos que circundam a regulação, e como eles interagem no processo de construção do ambiente financeiro de forma concreta. Apesar do presente trabalho partir de considerações nesse sentido, ele é fundamentalmente teórico, de análise da literatura acadêmica acerca da regulação prudencial e, fora da análise cuidadosa das linhas do que foi tratado especificamente nessa literatura, não irá se engajar em discussões de cunho político.

Num segundo plano de debates, pode se considerar algo chamado de "supervisão prudencial”, que diz respeito às necessidades técnicas e procedimentos metodológicos utilizados pelos reguladores para avaliar os critérios determinados pela política e regulação prudenciais na aplicação concreta dessas diretrizes. Em outras palavras, trata-se das dificuldades técnicas envolvidas no jogo de gato e rato travado entre reguladores e regulados, no campo da regulação prudencial. As questões levantadas são de ordem fundamentalmente técnica, e dizem respeito às necessidades de cognição dos elementos definidos na regulação prudencial. Como eu enxergo o risco a que está exposta uma instituição financeira em específico, e como eu enxergo o risco a que está exposto o sistema financeiro como um todo? Essas necessidades técnicas, de medição e avaliação, também fogem ao escopo do presente trabalho. Enquanto se pode considerar que o campo da política prudencial é demasiadamente abstrato, se comparado com o que é aqui proposto, o campo da supervisão prudencial é excessivamente concreto. O campo da regulação prudencial, objeto do presente trabalho, desta forma, situa-se no meio do caminho entre a política prudencial e a regulação prudencial. Além disso, como já ressaltado, trata-se de um trabalho de análise linha a linha do debate acadêmico crítico sobre o tema que se desenvolve no pós-crise, tal como protagonizado por Admati e Helllwig. O campo da supervisão prudencial é objeto de longo estudo da literatura técnica, e de autores como Owen (2000), e trata sobretudo da construção 
de indicadores factíveis e eficientes para o acompanhamento e monitoramento da regulação e política prudenciais.

Por fim, temos o que se pode chamar de regulação prudencial, e que tomamos pela definição de base daquilo que se estuda no presente trabalho. $\mathrm{O}$ campo da regulação prudencial constitui-se na análise crítica das normas que compõe, ou que se considera que devam compor, as exigências de capital e liquidez das instituições financeiras ${ }^{9}$. Além disso, deve-se considerar também o campo da regulação macroprudencial, que sai do escopo das instituições financeiras individualmente consideradas, e passa a analisar a solvência e liquidez do sistema financeiro como um todo, principalmente pela análise dos problemas de contágio (Admati e Hellwig, 2013, pg. 60). Assim, podemos considerar que o campo da regulação (macro)prudencial, objeto do presente trabalho, constitui-se no estudo dos critérios de capital, liquidez e contágio, que em conjunto representam a solvência das instituições financeiras, e de sistemas financeiros como um todo, quando observadas em conjunto.

Assim, como devemos compreender, para fins do presente trabalho, cada um dos elementos que compõe a regulação (macro)prudencial, capital, liquidez e contágio? A princípio, pode-se ter impressão de que capital faz referência aos ativos de uma instituição financeira. Todavia, a regulação de capital diz respeito à circunscrição dos passivos dessa instituição. As regras de capital tratam das formas pelas quais uma instituição financeira pode financiar seus investimentos. Especialmente, em que medida as instituições financeiras podem realizar seus investimentos com dinheiro emprestado, captado no mercado ou por seus depositários, e quanto essa mesma instituição financeira deve financiar seus investimentos com capital próprio, captado junto a seus acionistas. Assim, os critérios de capital estabelecidos pela regulação prudencial determinam o padrão dos passivos que uma instituição financeira deve ter. O objetivo, aqui, é garantir ao máximo que uma instituição financeira quebre.

Liquidez, por sua vez, é o campo da regulação prudencial que propriamente diz respeito aos ativos das instituições financeiras. Trata, assim, da regulação acerca da constituição de reservas, necessárias ao cumprimento tempestivo das obrigações assumidas

9 "That is, regulation could aim to mimic the capital and liquidity decisions which would be taken by bank controllers fully exposed to the costs of bank failure and thus to internalize the full costs of banks' activities. In terms of our typology of regulatory strategies, this is prudential regulation." (Armour et alii, 2016, p. 292). 
pelas instituições financeiras, conforme seus respectivos tempos de maturação. A regulação de liquidez, desta forma, determina também quais ativos podem, ou não, ser considerados para a constituição de reservas. Ou seja, quais ativos são considerados líquidos o bastante para, a qualquer tempo e com eficácia, caso necessário, serem convertidos em moeda corrente para o cumprimento adequado das obrigações. Problemas de liquidez em uma instituição financeira não necessariamente indicam problemas de solvência, apesar de ser bastante provável que as duas questões apareçam juntas. Problemas de liquidez podem ser causados apenas por erros de previsão no fluxo de caixa, fazendo com que a maturidade das obrigações assumidas, e dos ativos detidos, não se compatibilizem, de tal modo que naquele momento não se tem dinheiro em caixa o bastante para a satisfação das obrigações. Problemas de solvência, também, podem por vezes serem confundidos com problemas de liquidez. Após a crise de 2008, por exemplo, o governo da Irlanda assumiu que o problema de suas instituições financeiras era de liquidez ${ }^{10}$, garantindo então a dívida dessas instituições, para acalmar os credores. Como o problema, na realidade, era de solvência, as instituições garantidas quebraram, repassando para o governo daquele país as obrigações assumidas, o que gerou graves consequências para a economia. Também, como medida auxiliar à solução de problemas de liquidez, diversas jurisdições possuem políticas de garantia do crédito. No Brasil há o Fundo Garantidor do Crédito - FGC. Nos estados Unidos, o Federal Deposit Insurance Corporation - FDIC.

Contágio, por fim, se constitui no principal elemento da regulação prudencial surgido a partir da crise de 2008, e a partir do qual se constrói a ponte entre a regulação (micro)prudencial e a regulação macro prudencial. Como argumentam Admati e Hellwig (2013, pg. 60), quando se observa o ocorrido na crise de 2008, estima-se que as perdas decorrentes da dívida imobiliária norte-americana tenha sido da ordem de US\$ 500bi, montante relativamente pequeno se comparados aos cerca de $\$ 80$ trilhões de dólares detidos em ativos pelos bancos naquele momento, além de ter sido uma perda relativamente pequena se comparado aos \$ 5 tri de perdas decorrentes do bolha de tecnologia nos Estados Unidos,

${ }^{10}$ Em 2008 o governo da Irlanda edita o "act 18 of 2008", ou "Credit Institutions (Financial Support) Act 2008", segundo o qual se ofereceu ampla garantia governamental para o crédito dos bancos irlandeses. Essa medida, ao estilo de um seguro de crédito, é consequência regulatória de um diagnóstico de liquidez, e visava evitar o choque informacional iniciado pela crise nos Estados Unidos afetasse aquelas instituições. Entretanto, quando se revelou que a exposição das instituições irlandesas à divida imobiliária norte-americana era real e direta, revelou-se que em realidade os bancos estavam insolventes, e o Estado irlandês se viu obrigado a arcar com as perdas dessas instituições. Para mais informações sobre a lei, vide site do parlamento irlandês: 〈https://www.oireachtas.ie/en/bills/bill/2008/45/>, acesso em 23.07.2018. 
no início dos anos 2000. A grande diferença entre esses dois momentos, e o que fez uma perda relativamente pequena gerar consequências globais tão brutais, é o contágio. Os bancos detentores dos títulos da dívida imobiliária norte-americana estavam altamente endividados, e financiavam seus investimentos principalmente com crédito a curto e curtíssimo prazo (crédito compromissado) (Admati; Hellwig, 2013, p. 11). As perdas sofridas por esses bancos, dada a alta alavancagem, ameaçaram sua solvência, e sua capacidade de contrair novos empréstimos. Ao mesmo tempo, os fundos que realizavam empréstimos a curto e curtíssimo prazo deixaram de fazê-lo, diante das dúvidas com relação à solvência dessas instituições.

De modo genérico, quando há uma diminuição considerável no valor dos ativos de um banco, num primeiro momento incorrem em problemas de liquidez. Não há, desta forma, caixa suficiente para arcarem com suas obrigações. Em resposta, a solução é a venda de ativos ou o refinanciamento das dívidas. A venda generalizada de ativos deprecia seu valor e, além disso, deprecia o próprio mercado para aquele determinado ativo, reduzindo as possibilidades de capitalização com o mesmo. Caso não consigam refinanciar suas dívidas, e sem terem capital próprio para arcarem com as perdas, esses bancos certamente quebrariam. Com a quebra desses bancos, outros bancos que detém empréstimos contra eles deixariam definitivamente de receber e, novamente, por conta de sua alta alavancagem, não teriam capacidade de suportarem as perdas e quebrariam também. Esse efeito em cadeia é o que, para fins de regulação prudencial, se considera como "contágio". Trata-se, assim, do grau de interconectividade de um determinado sistema financeiro (ou sistema financeiro único e global), e de como cada uma das instituições envolvidas (a) têm condições de suportarem perdas; ou (b) transmitem as perdas que sofrem para outras instituições. A interconectividade entre as instituições financeiras e, consequentemente, as formas de desenvolvimento do contágio, pode se dar por duas formas principais, uma direta e outra indireta (Admati; Hellwig, 2013, pp. 61-64; Hellwig, 1995). Uma primeira forma de contágio, direta, se dá pela cadeia de obrigações de crédito e débito. De tal modo que, com a quebra de uma instituição, seus credores deixam de receber, e assim por diante. Outra forma de contágio, indireta, se dá quando, na tentativa de gerar liquidez através da venda de ativos, o mercado para aquele ativo se satura, e seus preços se depreciam, afetando também outros detentores do mesmo ativo.

Segundo Admati e Hellwig (2013, pp. 65-66), três fatores foram determinantes para que, em 2008, o efeito do contágio fosse tão deletério, fazendo com que perdas 
relativamente pequenas (cerca de US\$ 500 bilhões) tivessem impactos por todo o mundo. Em primeiro lugar, os títulos lastreados na dívida imobiliária norte-americana, que geraram a crise, eram detidos por instituições financeiras (não apenas bancos) ao longo de todo o globo. Em segundo lugar, como as instituições que detinham esses títulos estavam tão altamente alavancadas, detendo pouco capital com relação a seu débito, as preocupações com relação a sua solvência se espalharam rápido, e o efeito dominó entre as instituições credoras e devedoras se tornou uma preocupação geral. Em terceiro lugar, por fim, tem-se que o financiamento dessas instituições era feito fundamentalmente por débito de curto prazo tomado junto a outras instituições financeiras, principalmente fundos de Money Market, e não com depósitos. Ao contrário dos depositários, os fundos de Money Market não estavam protegidos (oficialmente) pelo seguro de crédito e, assim, ao primeiro sinal de insolvência de seus devedores, não renovou seus investimentos ou se recusou a fazer novos. Assim, em 2008, apesar de não ter havido propriamente uma corrida bancária de depositários, houve uma corrida de fundos que forneciam a liquidez utilizada pelas instituições financeiras na realização de seus investimentos, gerando efeitos similares e dando início a uma reação em cadeia que ocasionou a primeira crise financeira global do século XXI (Reinhart; Felton, 2008).

\subsection{A REGULAÇÃo PRUDENCIAL NO PRÉ-CRISE}

O primeiro momento da dissertação consistirá na elaboração de um panorama acerca do debate prudencial no pré-crise. Para tanto, considera-se necessário delinear o que se entende por pré e pós-crise, de modo a se definir também aí qual o recorte utilizado para o levantamento da literatura. Em seguida, serão apresentados os aspectos centrais do debate prudencial do pré-crise, os quais se consistem basicamente na (i) relevância dada às instituições financeiras individualmente consideradas e na (ii) centralidade do método CAMELS como mecanismo de verificação e monitoramento da higidez das instituições financeiras, o que dá margem considerável ao desenvolvimento de arbitragens regulatórias.

\subsubsection{DOIS MOMENTOS: O PRÉ E O PÓS-CRISE DE 2008}

A distinção entre pré e pós-crise de 2008, definida operacionalmente para as necessidades do presente trabalho, se limita a distinguir o estado em que o debate prudencial se encontrava logo antes da eclosão da crise, do debate prudencial que se desenvolve após e por consequência da crise. 
Ou seja, é possível que haja trabalhos prudenciais desenvolvidos em momento cronológico posterior à crise de 2008, mas que ainda assim não a levem em conta. Esses trabalhos não seriam de interesse para o presente projeto. O objetivo da análise a ser desenvolvida é também identificar de maneira sistemática - levando em conta o plano de fundo crítico tomado por marco teórico - a evolução do debate prudencial com a crise de 2008, tomando-se por eixo central o trabalho de Admati e Hellwig.

Assim, é central para o objetivo da dissertação que se identifique com clareza as condições anteriores e posteriores do debate. Quais elementos se mantém, quais elementos mudam, e em que medida mudam ou se mantém. Desta forma, no presente trabalho, quando se refere a pré-crise, está-se falando da situação do debate prudencial produzido até imediatamente antes da eclosão da crise de 2008. Quando se refere a pós-crise, está-se falando do debate prudencial que emergiu após e por conta da crise, tentando compreendêla ou, ao menos, levando-a em conta na construção de suas análises e argumentos.

\subsubsection{O DEBATE PRUDENCIAL NO PRÉ-CRISE: CENTRALIDADE DOS ASPECTOS MICRO- PRUDENCIAIS}

A noção de regulação prudencial, desenvolvida no pré-crise, constitui-se na determinação das condições institucionais de manutenção, higidez e solvência das instituições financeiras, quando o problema é observado no plano micro, e do sistema financeiro como um todo, quando se observa o problema no plano macro. Trata-se, assim, da identificação e intervenção nas falhas e processos do sistema financeiro que podem levar à sua crise e ruptura. A regulação prudencial no pré-crise é fundamentalmente uma técnica regulatória baseada no diagnóstico de solvência das instituições financeiras, e no estabelecimento de padrões mínimos de segurança para que não haja quebras. Uma instituição financeira insolvente tem enorme potencial para gerar crises sistêmicas de grandes proporções, e nesse contexto a regulação prudencial desempenha um papel central.

Tal processo de intervenção, como já dito, pode ser tanto visto na perspectiva dos atores e instituições quando singularmente considerados - regulação micro-prudencial quanto na perspectiva de um recorte amplo e geral do sistema financeiro - regulação macroprudencial. A questão macro-prudencial, no que concerne à literatura do pré-crise, como é o caso de Owen (2000), desenvolve-se pela agregação dos indicadores micro-prudenciais somados a análises macroeconômicas. Desse modo, a análise do aspecto macro da regulação 
propriamente prudencial, no pré-crise, é consequência da agregação de seu aspecto micro, o que as torna diretamente relacionadas, interdependentes e complementares.

Assim, uma das principais características do debate prudencial no pré-crise, é a centralidade dos aspectos micro-prudenciais. Tanto que as considerações macro-prudenciais, quando surgem, dão-se pela agregação de indicadores micro-prudenciais - no máximo somados a variáveis macroeconômicas. Não há ainda um desenvolvimento forte no debate prudencial a respeito de diferenças fundamentais e mesmo de incompatibilidades entre os aspectos regulatórios micro e macro-prudenciais.

\subsubsection{INDICADORES DE MONITORAMENTO DA HIGIDEZ INSTITUCIONAL}

Outro aspecto relevante do debate prudencial do pré-crise é o desenvolvimento do método CAMELS ${ }^{11}$ de definição e sistematização dos indicadores de solvência das instituições financeiras ${ }^{12}$ que fundamentam e guiam o desenvolvimento e aplicação da regulação prudencial, conforme apresentada por Owen (2000). Esse modelo define um conjunto de indicadores para instituições financeiras, tanto quantitativos quanto qualitativos, segundo o que se teria uma visão clara do grau de higidez dessas instituições e, quando agregados, da estabilidade e solidez de um sistema financeiro como um todo. São eles: (i) adequabilidade do capital; (ii) qualidade dos ativos; (iii) governança corporativa; (iv) receitas e lucratividade; (v) liquidez; e (vi) sensibilidade ao risco de mercado. A definição abaixo dos indicadores CAMELS extraio de Owen (2000).

Para além dos seis indicadores principais do modelo CAMELS, não se pode desconsiderar a importância também de outros indicadores de mercado para o debate do précrise, bem como a contextualização destes e demais indicadores analisados diante da conjuntura macroeconômica em que são analisados. Como indicadores de mercado, podemos considerar por exemplo o preço dos papeis financeiros em circulação, taxas

análise.

${ }^{11} \mathrm{O}$ nome CAMELS é a sigla em inglês para cada um dos indicadores levados em conta na

12 Ponto importante a acrescentar: instituições financeiras são muito similares quanto ao papel que desempenham como investidores institucionais. Algumas mais do que outras, certamente. Um fundo de previdência tem uma atuação enquanto investidor institucional muito mais proeminente e vinculada a sua função principal do que, por exemplo, um banco. De todo modo, o estudo da solvência das instituições financeiras, e de sua regulação, é algo que se manifesta de forma relativamente similar. Isso porque, apesar das peculiaridades - que são muitas - entre as diversas instituições do campo, quando agem como investidores institucionais suas preocupações convergem - quanto de capital posso expor a risco? Qual retorno preciso buscar para manter minhas obrigações assumidas? 
excessivas de juros oferecidas - que pode indicar alto risco do ativo -, o grau de confiança no crédito e demais investimentos, bem como a vulnerabilidade do país como um todo. Em adição, um contexto macroeconômico composto pela taxa de crescimento econômico, balança de pagamentos, inflação, taxa de juros, taxa de câmbio, explosões bruscas nas taxas de empréstimo e no preço dos ativos (que podem indicar bolhas), pode - e deve - servir como elemento de ponderação dos indicadores de mercado e prudenciais analisados para se compreender a higidez (e, na outra ponta, o risco de insolvência) de uma instituição financeira ou do próprio sistema financeiro como um todo.

\section{Adequabilidade do capital}

Constitui-se pela análise das (i) taxas agregadas de capital ponderadas pelo risco e pela (ii) frequência na distribuição das taxas de capital. Esses indicadores, segundo Owen (2000), demonstram a robustez das instituições financeiras a choques nos seus balanços. São, todavia, uma forma atrasada de diagnóstico, uma vez que quando se observa empiricamente o seu declínio, as instituições financeiras em geral já estão passando por sérios problemas.

As taxas agregadas de capital ponderadas pelo risco são uma das principais formas de avaliação da adequabilidade do capital. Uma queda nesse indicador pode sinalizar aumento na exposição ao risco da instituição financeira além de possíveis problemas de adequabilidade do capital. Com relação a esse indicador, uma possível alternativa para que se precise a análise seria levar em conta também a qualidade do capital. Assim, é possível que se estabeleça espécies de capital com relação à sua disponibilidade e capacidade de suportar perdas.

Outra possibilidade de análise da adequabilidade do capital é pela frequência da distribuição das taxas de capital. Constitui-se basicamente da mensuração da adequabilidade do capital aos riscos através da comparação entre instituições financeiras. Trata-se, assim, de um indicador comparado, que exige estudo próprio para sua verificação e mensuração.

\section{Qualidade dos ativos}

A deterioração dos ativos constitui-se num dos principais riscos à solvência das instituições financeiras. Assim, a confiança que se pode ter nas taxas e proporções de capital depende substancialmente dos indicadores de qualidade dos ativos.

Esses indicadores podem ser encontrados ao nível das organizações credoras quanto das instituições devedoras. Com relação às instituições credoras, pode-se centrar o 
olhar na (i) concentração setorial de crédito; (ii) concentração de crédito oferecido em moeda estrangeira; (iii) taxa de créditos não-performantes; (iv) concentração de crédito oferecido a instituições públicas deficitárias; (v) perfil de risco dos ativos da instituição; (vi) concentração de créditos vinculados a mesmos devedores; (vii) taxa de alavancagem medida pela razão entre ativos e capital.

A qualidade do portfólio de créditos da instituição financeira, também, depende diretamente da saúde e higidez da instituição devedora. Na perspectiva dessas instituições, pode-se centrar o olhar na (i) proporção entre débito e equity do devedor; (ii) na lucratividade dos setores corporativos; e (iii) no grau de endividamento dos devedores, especialmente naqueles lastreados em garantias reais.

\section{Governança corporativa}

A análise da governança corporativa das instituições financeiras, dadas as peculiaridades interinstitucionais, é especialmente relegada a uma visão qualitativa feita de organização para organização. É, assim, especialmente difícil que se agregue dados acerca da indicação de qualidade da governança corporativa das instituições, e a partir disso se extraia conclusões acerca da higidez sistêmica de um sistema financeiro.

Owen (2000, pg. 7) faz referência a três indicadores passíveis de serem auferidos quantitativamente acerca da robustez organizacional de instituições financeiras, quais sejam, (i) proporção dos gastos com relação às receitas; (ii) ganhos por empregado com relação ao total dos gastos e sua variação ao longo do tempo; (iii) expansão no número de instituições financeiras.

\section{Receitas e lucratividade}

Instituições financeiras que cronicamente não sejam lucrativas não são hígidas e têm risco de insolvência. Desta forma é relevante que se mantenha o monitoramento e controle dos índices de lucratividade dessas organizações. Quedas acentuadas na lucratividade podem indicar tendências à insolvência. Bem como, aumentos acentuados na lucratividade podem indicar aumento na agressividade da instituição financeira, resultado de um portfólio de investimentos de maior risco ou de um plano de negócios de curto prazo que não seja sustentável.

Indicadores de retorno dos ativos e indicadores de retorno obtidos por equity são formas de se avaliar a lucratividade de uma instituição financeira, mesmo que, quando 
observados, possam levar a conclusões dúbias acerca daquilo que efetivamente indicam. Por exemplo, Owen (2000) alerta que uma alta taxa pode indicar tanto alta lucratividade quanto baixa capitalização. Bem como, uma baixa taxa pode indicar tanto baixa lucratividade quanto alta capitalização. Os processos de investimento adotados pela companhia, portanto, devem ser levados em conta conjuntamente à análise da sua lucratividade. Além desses, outros indicadores possíveis são as taxas de receitas sobre gastos, bem como uma análise da qualidade dessas receitas e gastos, além de indicadores estruturais da instituição, como a alteração na taxa de juros, flutuação do spread bancário e flutuação, também, da margem de retorno dos investimentos.

\section{Liquidez}

Conforme coloca Owen (2000, pg. 8), instituições financeiras inicialmente solventes podem ter problemas de manutenção de suas atividades por conta de manejo ruim do fluxo de caixa de curto prazo. Os problemas de liquidez, todavia, podem se revelar e surgir por diversas formas, observáveis por exemplo através do portfólio de investimento da instituição financeira, da razão entre, e nesse ponto mais especificamente no contexto bancário, empréstimos e depósitos, além da relação entre ativos e contingências.

Também, indicadores de liquidez enfrentam o desafio de lidarem com uma medida em constante mudança, podendo se alterar rapidamente a depender de fatores circunstanciais incidentes sobre a organização.

\section{Sensibilidade a indicadores de risco de mercado}

Instituições financeiras em sentido amplo, como se observa aqui, operam com graus sempre elevados de diversificação. Ficam, assim, expostas a um ou mais aspectos dos riscos de mercado. Uma carteira muito grande composta por ativos voláteis pode indicar a vulnerabilidade da instituição financeira a variações no preço desses ativos.

Além disso, volatilidade no preço das commodities, riscos de câmbio em negociações com moeda estrangeira, de variação da taxa de juros e riscos de variação do equity. Todos esses pontos podem afetar instituições financeiras diferentemente a depender de sua natureza e funções institucionais, e do seu portfólio de investimentos. 


\subsubsection{PRIMEIRAS CONSIDERAÇÕES ACERCA DE UMA REGULAÇÃO MACRO-PRUDENCIAL}

Mesmo no pré-crise, surgem já no debate prudencial algumas propostas e considerações acerca de diferenças fundamentais entre os aspectos micro e macro prudenciais, bem como acerca da importância de revisão dos mecanismos regulatórios em vigência de modo a se evitar possíveis crises oriundas da incapacidade de controle sistêmico da regulação então vigente.

Segundo Faia e Schnabel (2015), autores como Hellwig (1995) já apresentavam preocupações macro-prudenciais. Além dele, Crocket (2000) teria iniciado um intenso debate no Bank for International Settlements (BIS) acerca da importância da dimensão macro-prudencial da estabilidade financeira, e da necessidade de se adotar medidas específicas para a solução deste tipo de problema.

A construção teórica de Hellwig (1995) no pré-crise já desenvolvia o elemento central daquilo que seria o alicerce da regulação macroprudencial, qual seja, o conceito de contágio. Desenvolvido brevemente acima, em tópico próprio, a noção de contágio é o elemento central para a compreensão de que o sistema financeiro está intensamente interconectado - sendo ‘interconexão' outro conceito central da regulação macroprudencial. Por outras palavras, Hellwig já salientava, em 1995, que existe uma densa trama contratual entre as instituições financeiras no mundo. Essa densa trama contratual faz com que haja obrigações de débito e crédito entre instituições espalhadas pelo mundo, de modo que o inadimplemento de uma instituição pode afetar várias outras. Quando o inadimplemento é relevante, como por exemplo aquele derivado da falência de um grande banco, ele pode iniciar uma reação em cadeia no sistema financeiro, espalhando-se pela trama contratual existente entre as instituições, e dessa forma provocar efeitos sistêmicos de grandes proporções. Hellwig (1995) apresenta essas conclusões a partir da análise da crise do mercado de $S \& L$ (savings and loans) nos Estados Unidos, na década de 1980. Já naquela oportunidade, Hellwig chama atenção para a densa interconexão do sistema financeiro global, e chama atenção para os elevados riscos de contágio. Chama a atenção principalmente para os altos índices de alavancagem das instituições financeiras em meados da década de 1990, de tal modo que mesmo choques (inadimplementos) pequenos em termos absolutos, poderiam ser relevantes e se espalhar (contágio) pela trama contratual, altamente interconectada, do sistema financeiro gerando crises sistêmicas. Hellwig já alertava, em meados da década de 1990, que o sistema financeiro estava propenso a crises de proporções 
globais dado a (i) altos índices de alavancagem das instituições financeiras; e (ii) elevada interconexão do sistema financeiro, propiciando fácil contágio em caso de choques.

\subsection{PROCESSO POLÍTICO DE REFORMA dA REGULAÇÃo PRUDENCIAL NO PÓS- CRISE}

Desde a crise de 2008, tem-se desenvolvido um intenso debate em diversos dos espaços públicos acerca do problema da regulação prudencial. Paralelamente ao debate teórico acadêmico, que é o principal foco deste trabalho, desenvolve-se um debate político que não pode ser deixado de lado, e que deve ser tido como plano de fundo quando da análise do debate acadêmico. Importante aqui, desta forma, considerarmos ao menos as linhas gerais do processo de discussão política e reforma da regulação prudencial que se constrói no póscrise. Tal processo político envolve outros campos da regulação prudencial, como resolução de instituições bancárias, comercialização de derivativos fora das câmaras de compensação (over the conter), entre outros tópicos que surgiram com a crise de 2008. Entretanto, diante do foco específico do presente trabalho, o enfoque aqui será no processo de reforma, especificamente, da regulação prudencial.

De modo geral (Bentz, Mayntz, 2015; pg. 175) os requisitos de capital e, de modo geral, a regulação prudencial, tornou-se o principal foco dos reguladores no pós-crise, sendo esse o campo da regulação financeira que recebeu mais debates e alterações concretas. Betnz e Mayntz (2015, pg. 175) consideram que houve um consenso entre os reguladores e autoridades prudenciais de que, depois da crise, seria necessário aumentar os requisitos de capital. Era essa a diretriz passada a eles por seus assessores técnicos e consultores. O sistema bancário e financeiro precisaria de critérios mais rígidos de capital se quisesse suportar melhor as crises.

Não se criou consenso, todavia, acerca de quanto capital deveria ser exigido dos bancos (Bentz, Mayntz, 2015; pg. 175). Diretamente relacionado às reservas de capital, também não se criou consenso acerca das regras de governança corporativa relativa aos bônus e pagamentos aos administradores e diretores dessas instituições, de modo a se evitar que houvessem incentivos à tomada desenfreada de riscos, à revelia dos interesses da sociedade e das próprias instituições que administram (Bentz, Mayntz, 2015; pg. 175). Até o momento (Bentz, Mayntz, 2015; pg. 175), essas regras de governança não sofreram mudanças substanciais, mas os requisitos de capital, ao menos, foram aumentados, nos limites e termos do Acordo de Basileia III. 
Essa área da regulação tem um longo histórico de coordenação e prática, que data do primeiro Acordo da Basileia, de 1988, passando pelo Acordo de Basileia II, de 2004 (Bentz, Mayntz, 2015; pg. 176). Ao longo de todo esse processo, do primeiro ao terceiro acordo da Basileia, o Comitê da Reserva Federal, dos Estados Unidos (US Federal Reserve Board, ou "FED") tomou a dianteira, delineando os caminhos a serem tomados pela regulação, por vezes em uníssono com o Banco da Inglaterra, e juntos frequentemente fizeram suas ideias e interesses prevalecerem nos órgãos decisórios da Basileia, abrindo caminho para mudanças substanciais em termos de requisito de capital e limites de alavancagem (Bentz, Mayntz, 2015; pg. 176). Os atores norte-americanos, em conjunto com os suíços e holandeses, fizeram passar no Basileia III níveis adicionais de capital para Instituições Financeiras Sistemicamente Importantes ("IFSI" ou, da sigla em inglês "SIFI" - Sistemicaly Important Financial Institution) (Bentz, Mayntz, 2015; pg. 176). Essa “coalizão", por sua vez, sofreu resistência dos franceses e Alemães, representantes de um sistema bancário fortemente interligado com o Estado (Bentz, Mayntz, 2015; pg. 176). Ao final, no que concerne à Basileia III, a união entre Estados Unidos e Inglaterra foi capaz de fazer valer regras mais estritas de capital, apesar dos esforços contrários de países como França e Alemanha (Bentz, Mayntz, 2015; pg. 176). A negociação de normas mais rígidas no plano internacional, como ocorreu em Basileia III, fez com que os atores interessados em amenizarem essas regras, quando fossem transplantadas para os respectivos níveis nacional e comunitário, tivessem mais dificuldades e dependessem de maiores esforços de lobby para que pudessem fazer valer seus interesses. Assim foi o caso da França e, especialmente, Alemanha (Bentz, Mayntz, 2015; pg. 176).

Como dito acima, o FED norte-americano, especialmente em conjunto com o Banco da Inglaterra, têm sido atores centrais na pressão internacional pelo estabelecimento de regras de capital e alavancagem mais rígidas, desde Basileia I em 1988. No contexto de Basileia III, já no pós-crise de 2008, a posição desses atores quanto à regulação prudencial não mudou (Ryan, Ziegler, 2015; pg. 68). Não obstante, nas negociações do Basileia III o papel dos Estados Unidos como definidores da pauta regulatória se enfraqueceu, apesar de ainda se ter mantido relevante (Ryan, Ziegler, 2015; pg. 68). Esse enfraquecimento se deve a um conjunto de situação. Um primeiro motivo, se deu pelo aumento no número de membros no Comitê da Basileia para Supervisão Bancária (“CBSB”), órgão responsável pelo debate e edição dos acordos da Basileia. O número de membros, por conta da crise de 2008 e da consequente ascensão do G20 como ator político central no processo global de 
reforma da regulação financeira ${ }^{13}$ (Ryan, Ziegler, 2015; pg. 68). Além disso, o FED e as autoridades prudenciais norte-americanas vinham enfraquecidas tanto internamente quanto no plano internacional, uma vez que o epicentro da crise se deu naquele país (Ryan, Ziegler, 2015; pg. 68). Além disso, personagens centrais nos Estados Unidos para a definição da política prudencial adotada por aquele país, Daniel Tarullo no governo do FED e Sheila Bair na condução do FDIC, a autoridade norte-americana de garantia dos depósitos. Tarullo e Bair adotaram posições rígidas em seus mandatos, no sentido de promoverem o recrudescimento das regras de capital e alavancagem no país (Ryan, Ziegler, 2015; pg. 6869).

Assim, apesar do enfraquecimento político, os Estados Unidos entraram nas negociações que resultaram no Basileia III com o objetivo de enrijecerem os requisitos de capital, tanto em termos qualitativos quanto quantitativos, em medida que tornasse as instituições financeiras capazes de suportar perdas consideráveis e enfrentar crises institucionais sem que isso levasse ao desenvolvimento de crises sistêmicas. Isso incluía tanto um aumento dos requisitos de capital, quanto um melhor detalhamento dos critérios de ponderação pelo risco dos ativos considerados pela regulação prudencial, e ainda pelo estabelecimento de critérios adicionais de capital para instituições que fossem consideradas IFSI (Ryan, Ziegler, 2015; pg. 69). Conforme dito acima, os Estados Unidos trabalharam juntos ao Reino Unido, suíça e Holanda na defesa de regras de capital mais rígida, contra os interesses de amenização dessas propostas defendidos principalmente pela França e Alemanha. No final, o esforço político de reforma da regulação patrocinado pelos estados Unidos, além do aumento dos requisitos de capital, centrou-se em três iniciativas: (a) estabelecimento de critérios adicionais de capital para IFSI; (b) critérios suplementares de alavancagem; e (c), no plano interno, desenvolvimento da Análise e Revisão Compreensiva de Capital (do inglês, Comprehensive Capital Analysis and Review, ou "CCAR"), que

\footnotetext{
${ }^{13}$ O G20 emerge no pós-crise como ator central no processo global de reforma da regulação financeira por uma série de motivos políticos e práticos. Tratava-se, à época, no órgão mais bem estruturado a tratar do assunto, por se tratar inicialmente de um encontro dos ministros da fazenda, ou cargos equivalentes, das vinte maiores economias do mundo. Inicialmente, desta forma, o G20 se constituía num órgão de debate econômicofinanceiro. Com a emergência da crise de 2008, os problemas dessa monta ganharam enorme relevância e, consequentemente, esse órgão antes especializado ganhou os holofotes e forte relevância política. Com esse fortalecimento, ocasionado pela crise, o G20 passou a ser frequentado por líderes de estado, que antes raramente participavam dos encontros. A partir desse movimento é que o G20 foi ganhando cada vez mais relevância como espaço de articulação política, tornando-se o órgão central que é hoje. Esse processo de ascenção do G20 como órgão central no processo de reforma da regulação financeira no pós-crise e, posteriormente, como órgão político central, é estudado por Mayntz (2015b).
} 
significou a implantação nacional de regras e critérios que foram barrados no desenvolvimento do Basileia III (Ryan, Ziegler, 2015; pg. 70-72).

Com relação aos requisitos adicionais para as IFSIs, os Estados Unidos partiram para o debate com a meta de $3 \%$ dos ativos ponderados pelo risco, o que se deveu muito à postura de Bair e tarullo. Com resistência, ao final o Acordo de Basileia III passou a contar com requisitos adicionais para as IFSI que variam entre 1 e $1,25 \%$ dos ativos ponderados pelo risco, a depender do tamanho e grau de conectividade da instituição financeira (Ryan, Ziegler, 2015; pg. 70). Internamente, aproveitou-se do sucesso parcial no plano internacional, para definir-se regras adicionais para IFSIs que chegam a 4,5\% dos ativos ponderados pelo risco (Ryan, Ziegler, 2015; pg. 71). Com relação aos critérios suplementares de alavancagem, os Estados Unidos, em conjunto com seus parceiros, Reino Unido, Holanda e Suíça, defenderam o estabelecimento de requisitos mínimos de capital que fossem rígidos, e não estivessem vinculados a ativos ponderados pelo risco (Ryan, Ziegler, 2015; pg. 71). Essa tentativa, todavia, foi fracassada, não tendo sido aprovada nas negociações do Basileia III (Ryan, Ziegler, 2015; pg. 72). Por fim, com relação ao CCAR, nos Estados Unidos, independentemente da redação final do Basileia III, os critérios mais rígidos de capital defendidos acabaram sendo incorporados nas regras da CCAR, que acabou se tornando o principal corpo de regulação prudencial no país (Ryan, Ziegler, 2015; pg. 70). Tanto que, por volta de 2014, as autoridades prudenciais norte-americanas estavam proibindo instituições financeiras de distribuírem dividendos até que atingissem os critérios determinados na CCAR (Ryan, Ziegler, 2015; pg. 70).

$\mathrm{Na}$ redação final do Acordo da Basileia III, ficou determinado que as reservas de capital deveriam conter um primeiro nível (Common Equity Tier 1, ou "CET1") composto por $7 \%$ dos ativos ponderados pelo risco ${ }^{14}$.

A postura do Reino Unido no que diz respeito à regulação prudencial, especialmente no que tange aos requisitos de capital, mudou consideravelmente entre os

${ }^{14}$ A ponderação dos ativos pelo risco é um dos grandes pontos de crítica, especialmente da corrente crítica capitaneada por Admati e Hellwig, desenvolvida no debate acadêmico sobre regulação prudencial. A ponderação pelo risco, por si só, que já vinha sendo aplicada no Basileia II, é capaz de ter criado incentivos no sentido de procura excessiva de papeis lastreados pela dívida imobiliária norte-americana, considerada de baixo risco e, consequentemente, "consumidora" de pouco capital nos termos da regulação prudencial vigente, conforme se observa no seguinte excerto: "Whatever the merits of stating equity requirements relative to risk-weighted assets may be in theory, in practice many banks have used this feature of the "Basel approach" to reduce their equity to a very small fraction of their total assets" (Admati; Hellwig, 2013, p. 177). 
anos que precederem a crise, e os ensinamentos que a sucederam (James; 2015, pg. 122). Historicamente, o Reino Unido sempre foi um centro da derregulação financeira. Todavia, com o desenvolvimento da crise de 2008 e a necessidade de evitar a quebra de dois de seus maiores bancos, criou o substrato político necessário, tornando premente o enrijecimento da regulação financeira. Nesse sentido, o principal receio das autoridades prudenciais competentes era o de que o sistema financeiro do Reino Unido, por ser tão relevante para a economia, era grande demais para ser salvo, caso houvesse uma crise generalizada (James; 2015, pg. 122). Como resposta, após a crise de 2008, as autoridades regulatórias do Reino Unido passaram a, internamente, promover intensa desalavancagem das instituições financeiras, ao mesmo tempo em que, no plano internacional, defendiam o enrijecimento das regras prudenciais (James; 2015, pg. 123). Para esse processo, foi central aos ingleses deterem uma série de cargos importantes nos comitês e subcomitês das agências regulatórias que, no plano internacional, definem a regulação prudencial, tanto que no processo de desenvolvimento do Basileia III, muito das diretrizes intelectuais que guiaram as reformas vieram ou do Reino Unido, ou dos Estados Unidos (James; 2015, pg. 123). O objetivo no plano internacional, principalmente, era o de adequar as regras internacionais ao grau de exigência que, no plano interno, por conta da pressão popular e das pressões políticas, as autoridades do Reino Unido foram obrigadas a tomar criando-se, assim, um padrão regulatório mínimo internacional, para que as instituições financeiras do Reino Unido não ficassem em desvantagem com relação às demais (James; 2015, pg. 123)

No contexto da União Europeia, desenvolveu-se um plano intermediário de debates, política e concretização da reforma da regulação prudencial. As peculiaridades da regulação comunitária criaram um ambiente situado no meio do caminho entre as autoridades nacionais e a atividade regulatória internacional, esta última centrada no comitê da Basileia. No caso da União Europeia, vem-se tradicionalmente transpondo as regras determinadas no plano internacional para o plano comunitário desde Basileia I, no final da década de 1980 (Quaglia, 2015; pg. 99). Nesse contexto, Basileia II e II foram transpostos para o plano comunitário através das Diretrizes para Requisitos de Capital de I a III (Capital Requirements Directive, ou “CRD”), principal diploma de regulação prudencial da União Europeia (Quaglia, 2015; pg. 99). No curso das negociações de Basileia III, países como Estados Unidos e Reino Unido, acompanhados de Suíça e Holanda, buscaram fazer valer as preferências determinadas internamente acerca de regras mais rígidas de capital, tendo sofrido a pressão contrária de países como França e Alemanha, interessados em manterem 
regras mais brandas dadas as peculiaridades de seu sistema financeiro. Não tendo tido completo sucesso no plano internacional, França e Alemanha enxergaram no plano comunitário, onde sua influência era maior, nova possibilidade de fazerem valer seus interesses, amenizando as regras de capital estabelecidas com Basileia III (Quaglia, 2015; pg. 99). Isso representou uma posição desunida da União Europeia nas negociações do Basileia III, enfraquecendo sua posição enquanto grupo político (Quaglia, 2015; pg. 100). Também, isso afetou profundamente o resultado final da reforma regulatória que se desenvolveu no contexto da União Europeia. Na negociação comunitária que se seguiu ao Basileia III, para o desenvolvimento do pacote regulatório das Diretrizes para Requisitos de Capital IV (“CRD IV”), ficou evidente também esse conflito (Quaglia, 2015; pg. 100-102). Dentre as diferenças entre a CRD IV e o Basileia III, ressalta-se os requisitos de capital mais brandos ${ }^{15}$, bem como a conceituação mais ampla de recursos que podem ser determinados como "líquidos" para fins de constituição de reservas (Quaglia, 2015; pg. 102). Também, nas negociações do CRD IV, os britânicos não conseguiram fazer valer sua intenção de implantar limites dos bônus e pagamentos dos administradores das instituições financeiras (Quaglia, 2015; pg. 102).

A Alemanha, por sua vez, acaba sendo um ator peculiar no debate político que leva à reforma da regulação prudencial no pós-crise. O foco da ação política desse país é, em todas as arenas das quais participa, a defesa dos interesses de seu sistema financeiro peculiar, formado em parte considerável por instituições de natureza híbrida, com participação pública e privada, utilizadas também para o financiamento das atividades estatais (Goldbach; Zimmermann, 2015, pg. 140). Nesse sentido, o grupo de agentes alemães agindo nos órgãos multilaterais têm por missão a manutenção de requisitos de capital reduzidos, de modo a manter a capacidade de financiamento dessas instituições. No plano internacional, composto por G20, FSB e BCBS, entre outros órgãos, a capacidade de pressão da Alemanha acaba se diluindo diante de outros atores com interesses distintos e força política considerável. Inglaterra e Estados Unidos, especialmente, por terem sido especialmente afetados pela crise, traziam a missão de endurecimento da regulação prudencial (Goldbach; Zimmermann, 2015, pg. 142). Desta forma, pode-se dizer que nesse

${ }^{15}$ Como, por exemplo, uma definição mais branda de CET 1, para fins de determinação de capital, e redução nos percentuais utilizados pelas regras de alavancagem (Quaglia, 2015; pg. 100). Ao menos, no contexto europeu, o CRD IV manteve a permissão às autoridades nacionais para que estabelecessem maiores requisitos de capital, caso considerassem necessário, o que se deu contra aos interesses dos franceses e alemães, mas a favor dos interesses dos britânicos (Quaglia, 2015; pg. 102). 
sentido a Alemanha não encontra grande sucesso no plano internacional. Todavia, no plano comunitário, de União Europeia, onde sua capacidade de pressão é consideravelmente maior, vai agir de modo a diluir as mudanças e diretrizes definidas no plano internacional, sobretudo a partir da flexibilização das regras de ponderação dos ativos pelo risco (RWA), e das especificações contábeis para operacionalização das regras da Basileia (Goldbach; Zimmermann, 2015, pg. 154). Essas mudanças serão ainda mais diluídas quando se passa para o plano nacional (Goldbach; Zimmermann, 2015, pg. 155). 


\section{CONCLUSÃO}

No presente trabalho se analisou o debate sobre regulação prudencial surgido a partir da crise de 2008, travado entre A\&H e seus interlocutores, notadamente, Gary Gorton, Gunther Teubner e John Armour ${ }^{80}$.

Analisando a argumentação desenvolvida entre os autores se conclui que, de modo geral, A\&H se situam em posição isolada, e consideravelmente crítica, no contexto desse debate. São os autores que de modo mais incisivo evidenciam problemas estruturais do sistema financeiro, e propõe soluções e medidas de reforma regulatória não restritas apenas à regulação prudencial observada de modo estrito (requisitos de liquidez e capital), mas sim propõe toda uma política prudencial que deve ser adotada pelo estado para que se possa alterar a estrutura de incentivos e desincentivos nas quais se inserem os atores centrais para o desenvolvimento do sistema financeiro, e dessa forma se possa criar as condições necessárias para que esse sistema financeiro se torne mais sólido e resistente a choques. Deve-se considerar também que Hellwig (1995) já evidenciava em meados da década de 1990 os problemas que vieram a causar a crise de 2008 - se não propriamente 'causaram', no sentido utilizado por Gary Gorton de forma restritiva para descrever apenas o primeiro choque a partir do qual se desenvolveu a crise, ao menos fizeram com que ela tomasse proporções globais e fortemente prejudiciais, quais sejam, interconexão e contágio decorrente da elevada alavancagem das instituições.

De modo específico, A\&H diverge de Gary Gorton principalmente com relação ao diagnóstico acerca das causas da crise, mas também com relação às possibilidades de reforma da regulação. Quanto ao diagnóstico, Gorton é categórico: a crise de 2008 foi uma crise de liquidez, causada por um choque informacional que transformou crédito insensível à informação em crédito sensível à informação. Essa transformação teria travado o mercado de crédito, de modo que as instituições financeiras não conseguiram refinanciar suas dívidas e a partir daí ocorreram os problemas de solvência. A\&H criticam o diagnóstico de Gorton, especialmente com relação à desconsideração de determinados elementos que foram centrais para a disseminação e seriedade da crise, não tanto com relação ao primeiro choque informacional. Ou seja, A\&H concordam que o choque descrito por Gorton de fato ocorreu,

${ }^{80}$ Conforme salientado na introdução deste trabalho, John Armour consta como primeiro autor em obra coletiva relevante, na qual se desenvolve crítica ao trabalho de A\&H. 
mas consideram que ele não teria sido central para as consequências da crise de 2008. Central para tais consequências, defendem $\mathrm{A} \& \mathrm{H}$, teriam sido problemas de solvência, estruturais do sistema financeiro, em decorrência do elevado grau de endividamento das instituições que o compõe. A proposta de reforma da regulação prudencial é elemento secundário em Gorton, mas ainda assim relevante. Com relação a esse ponto, Gorton defende reformas direcionadas à ampliação do seguro de crédito, de modo a evitar problemas de liquidez. A crítica de A\&H quanto à proposta de Gorton decorre da divergência quanto ao diagnóstico: extensão do seguro de crédito apenas agravaria o problema num cenário de solvência, pois alastraria ainda mais os riscos para as instituições (possivelmente governamentais, ou financiadas com dinheiro público) garantidoras.

A divergência entre A\&H e John Armour, por sua vez, diz respeito também ao diagnóstico e propostas de reforma, mas principalmente quanto a aspectos teóricos da regulação de capital. Trata-se da divergência acerca de se incrementos nos requisitos de capital são custosos para as instituições financeiras e, consequentemente, reduzem o seu valor de mercado, tornando tais negócios menos atrativos para atuais e potenciais investidores. Armour defende que o financiamento com capital é mais custoso, para as instituições financeiras, do que o financiamento por débito, e que por isso é necessário, para o valor e rentabilidade (e portanto atratividade) da atividade bancária (especialmente) que os requisitos de capital sejam mantidos em níveis ótimos, determinados econometricamente, mas de modo geral relativamente baixos. Armour fundamenta seu argumento, sobretudo, na inaplicabilidade do teorema de Modigliani Miller às instituições bancárias. Em linhas gerais, o teorema de Modigliani Miller postula que alterações na estrutura de financiamento de uma firma não geram alterações relevantes no seu valor. Tanto A\&H, quanto o próprio Merton Miller, consideram que o teorema de Modigliani Milller é aplicável aos bancos e que, portanto, não haveriam empecilhos para o aumento dos requisitos de capital. De nossa parte, concluímos que há elementos relevantes dos bancos, que não foram analisados explicitamente nem por A\&H nem por Merton Miller, e que podem significar a inaplicabilidade do teorema de Modigliani-Miller a essas instituições. Esse tópico, não obstante, merece aprofundamento teórico e empírico próprios, sendo possível objeto de desenvolvimentos posteriores.

Gunther Teubner possui abordagem teórica consideravelmente distinta da de $\mathrm{A} \& \mathrm{H}$, sendo ele um dos principais nomes da teoria dos sistemas e sociologia jurídica contemporânea, ao passo que aqueles últimos são teóricos econômicos com vinculação 
heterodoxa e neoinstitucionalista. Apesar dessas diferenças, ambos os autores analisam o mesmo objeto e, nesse contexto, buscam desenvolver um diagnóstico do problema e propostas de reforma regulatórias estruturais para solução/prevenção do problema. No caso, ambos tentam diagnosticar as causas da crise de 2008 e, na sequência, propõe medidas de reforma regulatória para modificação estrutural do sistema financeiro. Apesar de nenhum dos autores se utilizar desse vocabulário, estão ambos abordando a resposta regulatória à crise de 2008 como um problema de política prudencial, que deve se estender para além dos limites restritos da regulação prudencial (regras de liquidez e capital), para promoverem modificações estruturais do sistema. Dessa forma, diante da similaridade entre o objeto analisado por Teubner e A\&H, apesar da diferença de corrente teórica, é possível traçar um diálogo crítico entre os autores. Nesse sentido, há uma divergência substantiva entre os autores no que diz respeito às causas da crise, e à regulação de liquidez. Teubner constrói seu argumento pressupondo que a crise de 2008 foi um problema de corrida bancária ocorrida em bancos comerciais, o que em realidade não ocorreu. Todo o desenvolvimento da crise de 2008 se deu em bancos de investimento, estruturalmente distintos dos bancos comerciais, e por mecanismos distintos das corridas bancárias tradicionais - conforme desenvolvido por Gary Gorton. Também, Teubner propõe a instituição do 'plain money', técnica de regulação prudencial através da qual os bancos devem manter 100\% dos depósitos à vista captados em reservas, acompanhados de mecanismos para minimização dos efeitos da consequente retração da oferta de liquidez no mercado. Entretanto, corridas bancárias tradicionais, praticadas por depositários (à vista) em bancos comerciais, não são um problema real desde a instituição de mecanismos de seguro de crédito para essas instituições. Nos Estados Unidos, não ocorrem corridas bancárias tradicionais desde 1934, com a instituição do FDIC. O 'plain money', também, não resolve o problema de solvência dos bancos de investimento, uma vez que estas instituições não se financiam com depósitos à vista, mas sim com empréstimos captados no mercado, seja pela forma de dívida securitizada, crédito compromissado (shadow banking), depósitos a prazo ou outros mecanismos não disponíveis para o grande público. 


\section{BIBLIOGRAFIA}

AALBERS, Manuel B. The Financialization of Home and the Mortgage Market Crisis. Competition \& Change, vol. 12, n. 2, junho 2008, pp. 148-166.

ABOURA, Sofiane; LEPINETTE, Emmanuel. Do banks satisfy the Modigliani-Miller theorem? Economics Bulletin, AccessEcon, vol. 35, n. 2, 2015, pp. 924-935.

ACHARYA, Viral V. A theory of systemic risk and design of prudential bank regulation. Journal of Financial Stability 5. Elseviar, Amsterdam, 2009, pgs. 224-255.

ACHARYA, Viral; ENGLE, Robert; PIERRET, Diane. Testing macroprudential stress tests: the risk of regulatory risk weights. Journal of Monetary Economics 65. Elsevier, 2014, pgs. 36-53.

ADMATI, Anat; HELLWIG, Martin. The Bankers' New Clothes: What's Wrong with Banking and What to Do about It. Princeton University Press, Edição do Kindle, 2013. ADMATI, Anat; DEMARZO, Peter M.; HELLWIG, Martin F.; PFLEIDERER, Paul. Fallacies, Irrelevant Facts, and Myths in the Discussion of Capital Regulation: Why Bank Equity is Not Expensive. Reprints of the Max Planck Institute for Research on Collective Goods n. 42, Bonn, 2010.

Debt Overhang and Capital Regulation.

Working Paper No. 3114, Stanford Graduate School of Business, março 2012.

AGÉNOR, Pierre-Richard; ALPER, Koray; DA SILVA, Luiz A. Pereira. Capital requirements and business cycles with credit market imperfections. Journal of Macroeconomics 34. Elsevier, Amsterdam, 2012, pgs. 687-705.

AGÉNOR, Pierre-Richard; ALPER, Koray; DA SILVA, Luiz A. Pereira. Sudden floods, macroprudential regulation and stability in an open economy. Journal of International Money and Finance 48. Elsevier, Amsterdam, 2014, pgs. 68-100.

AGÉNOR, Pierre-Richard; DA SILVA, Luiz A. Pereira. Macroprudential regulation and the monetary transmission. Journal of Financial Stability 13. Elsevier, Amsterdam, 2014, pg. 44-63. 
AIKMAN, David; NELSON, Benjamin; TANAKA, Misa. Reputation, risk-taking, and macroprudential policy. Journal of Banking \& Finance 50. Elsevier, Amsterdam, 2015, pgs. $428-439$.

AIZENMAN, Joshua. On the paradox of Prudential regulations in the globalized economy: International Reserves and the crisis a reassessment. NBER Working Paper Series 14779. National Bureau for Economic Research, Cambridge, 2009.

AKRAM, Farooq Q. Macro effects of capital requirements and macroprudential policy. Economic Modelling 42. Elsevier, Amsterdam, 2014, pgs. 77-93.

ALEXANDER, Gordon J.; BAPTISTA, Alexandre M.; YAN, Shu. Bank regulation and international financial stability: A case against the 2006 Basel framework for controlling tail risk in trading books. Journal of International Money and Finance 43. Elsevier, Amsterdam, 2014, pgs. 107-130.

ALTMANN, Roger. Modern history's greatest regulatory failure. Financial Times, 17 de setembro de 2008 .

ANGELONI, Ignazio; FAIA, Ester. A tale of two policies: Prudential regulation and monetary policy with fragile banks. Kiel Working Paper 1569. Kiel Institute for the World Economy, Kiel, 2009.

APPLEBAUM, Binyamin. When She Talks, Banks Shudder. New York Times, 9 de agosto de 2014.

ARMOUR, John; AWREY, Dan; DAVIES, Paul; ENRIQUES, Luca; GORDON, Jeffrey; MAYER, Colin; PAYNE, Jeniffer. Principles of Financial Regulation. Oxford University Press, Oxford, Edição Kindle, 2016.

ARNOLD, Bruce et alii. Systemic risk, macroprudential policy frameworks, monitoring financial systems and the Evolution of capital adequacy. Journal of Banking \& Finance 36. Elsevier, Amsterdam, 2012, pgs. 3125-3132.

BAKER, Andrew. The Bankers' Paradox: The Political Economy of Macroprudential Regulation. SRC Discussion Paper 37. Systemic Risk Centre - London School of Economics, Londres, 2015.

BAKER, Andrew. The gradual transformation? The incremental dynamics of macroprudential regulation. Regulation \& Governance 7. Wiley Publishing, Haboken, 2013, pgs. 417-434. 
BALLING, Morten. Modigliani-Miller, Basel 3 and CRD 4. SUERF Policy Note, n. 2, SUERF The European Money and Finance Forum, outubro 2015.

BENZ, Arthur; MAYNTZ, Renate. The Multilevel Dynamics of Regulatory Reform. capítulo em Negotiated Reform: The multilevel governance of financial regulation. Mayntz, Renate (ed.). Max Planck Institute for the Study of Societies, ed. Campus Verlag, 2015, pp. 163-190.

BIANCHI, Javier; MENDOZA, Enrique G. Overborrowing, financial crises and 'macroprudential' taxes. NBER Working Paper Series 16091. National Bureau for Economic Research, Cambridge, 2010.

BLACK, Julia. Managing Regulatory Risks and defining the Parameters of Blame: A Focus on the Australian Prudential Regulation Authority. Law \& Policy, vol. 28, n. 1. Blackwell Publishing, Haboken, 2006, pgs 1-30.

BLANCHARD, Olivier et alii. Rethinking Macro Policy II: Getting granular. IMF Staff Discussion Note SDN/13/03. International Monetary Fund, Washington D.C., 2013.

BLUHM, Marcel; KRAHNEN, Jan Pieter. Systemic Risk in an interconnected banking system with endogenous asset markets. Journal of Financial Stability 13. Elsevier, Amsterdam, 2014, pgs. 75-94.

BORIO, Claudio; TSATSARONIS, Kostas. Accounting and Prudential regulation: from uncomfortable bedfellows to perfect partners? Journal of Financial Stability 1. Elsevier, Amsterdam, 2004, pgs. 111-135.

BORIO, Claudio; ZHU, Haibin. Capital regulation, risk-taking and monetary policy: A missing link in the transmission mechanism? Journal of financial Stability 8. Elsevier, Amsterdam, 2012, pgs. 236-251.

CALEM, Paul; ROB, Rafael. The Impact of Capital-Based Regulation on Bank RiskTaking. Journal of Financial Intermediation 8. Academic Press, Cambridge, 1999, pgs. 317-352.

CERRONE, Rosaria et alii. Does Prudential regulation contribute to effective measurement and management of interest rate risk? Evidence from italian banks. Journal of Financial Stability 30. Elsevier, Amsterdam, 2017, pgs. 126-138.

CHESNOKOVA, Maria. Application of Modigliani-Miller theorem to banking sector. Economics and Finances, Université Paris I Panthéon-Sorbonne, 2015. 
CINTRA, Marcos Antonio Macedo; FREITAS, Maria Cristina Penido. As Megainstituições e a Instabilidade Financeira: os desafios para a Regulamentação Prudencial. Revista de Economia Política, vol. 20, n. 2. Centro de Economia Política, São Paulo, 2000, pgs. 157-167.

CLEMENT, Piet. The term "macroprudential": origins and Evolution. BIS Quarterly Review. Bank for International Settlements, Basle, 2010, pgs. 59-67.

CLINE, William R. Testing the Modigliani-Miller Theorem of Capital Structure Irrelevance for Banks. Working Paper Series WP 15-8, Peterson Institute for International Economics, abril 2015.

COLANDER, David et alii. The Financial Crisis and The Systemic Failure of Academic Economics. Kiel Working Paper 1489. Kiel Institute for the World Economy, Kiel, 2009.

COUPPEY, Jézabel; MADIÈS, Philippe. L’éfficacité de la réglamentation prudentielle des banques à la lumière des approches théoriques. Revue d'économie financière 39. Association d'économie financière, Paris, 1997, pgs. 95-124.

CREAMER, Daniel; DOBROVOLSKY, Sergei P.; BORENSTEIN, Israel. Capital in Manufacturing and Mining: Its Formation and Financing. Journal of Economic History, vol. 22, n. 1, 1960.

CROCKET, Andrew. Marrying the micro- and macro-prudential dimentions of financial stability. BIS Speech, Basel, 2000.

CRONIN, Brenda. Handicapping the 2013 Economics Nobel. The Wall Street Journal, Real Time Economics, 10 de outubro de 2013.

DEUTSCHMANN, Christoph. Limits to Financialization: Sociological Analyses of the Financial Crisis. Archives of European Sociology, LII, 3. Cambridge University Press, Cambridge, 2011, pgs. 347-389.

DIAMOND, Douglas; DYBVIG, Philip. Bank Runs, Deposit Insurance, and Liquidity. Journal of Political Economy, junho, 1983.

DIAMOND, Douglas. Financial Intermediation and Delegated Monitoring. Review of Economic Studies, julho, 1984.

Monitoring and Reputation: The Choice Between Bank Loans

and Directly Placed Debt, agosto, 1991. 
DIAMOND, Douglas; RAJAN, Raghuran. Liquidity Risk, Liquidity Creation and Financial Fragility: A Theory of Banking, Journal of Political Economy, abril, 2001.

Fear of fire sales, illiquidity seeking, and credit freezes, The Quarterly Journal of Economics, maio, 2011.

DI LASIO, Giovani. Incentives and financial crisis: Microfounded macroprudential regulation. Journal of Financial Intermediation 22. Elsevier, Amsterdam, 2013, pgs. 627-638.

DODD, Randall. Derivatives, the shape of international capital flows and the virtues of prudential regulation. WIDER Discussion Papers 93. World Institute for Development Economics, Bonn, 2002.

DÖRRE, Klaus; LESSENICH, Stephan; ROSA, Hartmut. Sociology, Capitalism, Critique. Trad. Jan-Peter Herrmann e Loren Balhorn. Verso, Londres, 2015.

DURAN, Miguel A.; LOZANO-VIVAS, Ana. Risk shifting in the US banking system: an empirical analysis. Journal of Financial Stability 13. Elsevier, Amsterdam, 2014, pg. 64-74.

EICHENGREEN, Barry; ROSE, Andrew. Capital controls in the 21st Century. Journal of International Money and Finance 48. Elsevier, Amsterdam, 2014, pgs. 1-16.

FAIA, Ester; SCNABEL, Isabel. The road from micro-prudential to macro-prudential regulation. Em FAIA, Ester et alii (eds): Financial Regulation: A Transatlantic Perspective. Cambridge University Press, Cambridge, 2015.

FURLONG, Frederick; KEELEY, Michael. Capital Regulation and Bank Risk-Taking: a note. Journal of Banking and Finance 13. Elsevier, North-Holland, 1989, pgs. 883-891. GATZER, Nadine; WESKER, Hannah. A Comparative Assessment of Basel II/III and Solvency II. The Geneva Papers 37. The International Assossiation for the Study of Insurance Economics, Geneva, 2012, pgs. 539-570.

GAUTHIER, Céline; LEHAR, Alfred; SOUISSI, Moez. Macroprudential capital requirements and systemic risk. Journal of Financial Intermediation 21. Elsevier, Amsterdam, 2012, pgs. 594-618.

GLOCKER, Christian; TOWBIN, Pascal. Reserve requirement as a macroprudential instrument - empirical evidence from Brazil. Journal of Macroeconomics 44. Elsevier, Amsterdam, 2015, pgs. 158-176. 
GOLDBACH, Roman; Zimmermann, Hubert. Germany in the Context of the Multilevel Reform Process. capítulo em Negotiated Reform: The multilevel governance of financial regulation. Mayntz, Renate (ed.). Max Planck Institute for the Study of Societies, ed. Campus Verlag, 2015, pp. 139-162.

GORTON, Gary. Slapped by the Invisible Hand: The Panic of 2007. Financial Management association Survey and Synthesis, Oxford university Press, Edição do Kindle, 2010.

GREIF, Avner. Institutions and the Path to the Modern Economy. Cambridge University Press, Cambridge, 2006.

GREIF, Avner; LAITIN, David A. A Theory of Endogenous Institutional Change. American Political Science Review 98. Cambridge University Press, Cambridge, 2006. HANSON, Samuel G.; KASHYAP, Anil K.; STEIN, Jeremy C. A Macroprudential Approach to Financial Regulation. Journal of Economic Perspectives, Vol5, No 1. American Economic Association, Nashvile, 1991, pgs. 3-28.

HELLMAN, Thomas; MURDOCK, Kevin; STIGLITZ, Joseph. Liberalization, Moral Hazard in Banking, and Prudential Regulation: Are Capital Requirements Enough? The American Economic Review, vol. 90, n. 1. American Economic Association, 2000, pgs. 147-165.

HENDRICKSON, Jill M. Regulation and Instability in U.S. Commercial Banking: A History of Crises. Palgrave Macmillan, Hampshire, 2011.

HELLWIG, Martin F. Systemic aspects of risk management in banking and finance. Schweizerische Zeitschrift für Volkswirtschaft und Statistik 131(IV). Schweizerische Gesellschaft für Volkswirtschaft und Statistik, Zurich, 1995.

HOGAN, W. P.; SHARPE, I. G. Prudential Regulation of Bank Ownership and Control. Economic Analysis and Policy, vol. 19, n. 1. Elsevier, Amsterdam, 1989, pgs. 73-89. JACKSON, Patricia et alii. Capital Requirements and Bank Behaviour: The Impact of the Basle Accord. Basle Comittee on Banking Supervision Working Papers 1/1999. Bank for International Settlements, Basle, 1999.

JEANNE, Olivier; KORINEK, Anton. Macroprudential Regulation Versus Mopping up After the Crash. NBER Working Paper Series 18675. National Bureau of Economic Research, Cambridge, 2013. 
JEANNE, Olivire; KORINEK, Anton. Macroprudential policy beyond banking regulation. Financial Stability Review 18. Banque de France, França, 2014, pgs. 163171.

JAMES, Scott. The UK in the Multilevel Process of Financial Market Regulation: Global Pace-Setter or National Outlier? capítulo em Negotiated Reform: The multilevel governance of financial regulation. Mayntz, Renate (ed.). Max Planck Institute for the Study of Societies, ed. Campus Verlag, 2015, pp. 121-138.

JÚNIOR, Claofas S.; ANDRADE, Rafael J.; BRANDI, Vinicius R. (orgs). Estudos sobre Regulação Financeira. Banco Central do Brasil, Brasília, 2017.

JÚNIOR, Ronaldo Porto Macedo. O Método de Leitura Estrutural. Cadernos Direito GV vol. 4, n. 2 - caderno 16. Fundação Getúlio Vargas, São Paulo, 2007.

KASHYAP, Anil K., TSOMOCOS, Dimitrios P., VARDOULAKIS, Alexandros P. How does Macroprudential Regulation change Bank Credit Supply. NBER Working Paper Series 20165. National Bureau of Economic Research, Cambridge, 2014.

KAUFMAN, George G. Too big to fail in banking: What does it mean? Journal of financial Stability 13. Elsevier, Amsterdam, 2014, pgs. 214-223.

KREGEL, Jan. Minsky and dynamic macroprudential regulation. Public Policy Brief 131. Jerome Levy Economics Institute of Bard College, Blithewood, 2014.

KRIPPNER, Greta R. The Financialization of the American Economy. Socio-Economic Review 3. Oxford University Press, Oxford, 2005, pgs. 173-208.

KRIPPNER, Greta R. The Political Economy of Financial Exuberance. Em LAUNSBURY, Michael; HIRSCH, Paul M. (eds.). Markets on Trial: The Economic Sociology of the US Financial Crisis: Part B. Emerald, Bingley, 2010, pgs. 141-176.

KRIPPNER, Greta R. Capitalizing on Crisis: the political origins of the rise of finance. Harvard University Press, Cambridge, 2012.

KRISHNAMURTHY, Arvind; NAGEL, Stefan; ORLOV, Dimitry. Sizing Up Repo. NBER Working Paper No. 17768, National Bureau of Economic Research, janeiro 2012.

LIEDTKE, Patrick M. Insurance Activity as a Regulatory Object - Trends and Developments and thei Appretiation in the Context of Post-Crisis Global Markets. em 
Insurance Regulation Reflections for a Post-Crisis World. The Geneva Association, Genebra, 2012, pgs. 21-33.

MCLEAY, Michael; RADIA, Amar; THOMAS, Ryland. Money creation in the modern economy. Quarterly Bulletin Q1, Bank of England, 2014.

MAYNTZ, Renate (ed.). Negotiated Reform: The multilevel governance of financial regulation. Max Planck Institute for the Study of Societies, ed. Campus Verlag, 2015.

MAYNTZ, Renate. International Institutions in the Process of Financial Market Regulatory Reform. capítulo em Negotiated Reform: The multilevel governance of financial regulation. Mayntz, Renate (ed.). Max Planck Institute for the Study of Societies, ed. Campus Verlag, 2015, pp. 37-64.

MENDECINO, Caterina; PUNZI, Maria Teresa. House prices, capital inflows and macroprudential policy. Journal of Banking \& Finance 49. Elsevier, Amsterdam, 2014, pgs. 337-355.

MILLER, Merton. Do the M\&M propositions apply to banks? Journal of Banking \& Finance, vol. 19, Elsevier Science, pp. 483-489.

MISHKIN, Frederic S. Prudential Supervision: why is it importante and what are the issues? NBER Working Paper Series 7926. National Bureau for Economic Research, Cambridge, 2000.

MITCHENER, James Kris. Are Prudential spervision and regulation pillars of financial stabillity? Evidence from the great depression. NBER Working Paper Series 12074. National Bureau for Economic Research, Cambridge, 2006.

MODIGLIANI, Franco; MERTON, Miller. The Cost of Capital, Corporation Finance and the Theory of Investment. The American Economic Review, vol. 48, n. 3, junho, 1958, pp. 261-297.

OWEN, Evans et alii. Macroprudential Indicators of Financial System Soundness. Occasional Paper 192. International Monetary Fund, Washington D.C., 2000.

PEACH, Phillip. Shadow Banking: Legal Issues of colateral assets and insolvency law. Policy department - European Union, 2013.

PEACH, Phillip. The need for na international instrument of the enforceability of close-out netting in general and in the context of banking resolution. UNIDROIT Study Group of Principles and rules on the netting of financial instruments, Roma, 2011. 
PEACH, Phillip. The Value of Insolvency Safe Harbours. LSE Working Papers 9/2015. LSE Law Department, Londres, 2015.

PELÁEZ, Carlos M.; PELÁEZ, Carlos A. Regulation of Banks and Finance: Theory and Policy after the Credit Crisis. Palgrave Macmillan, Hampshire, 2009.

PFLEIDERER, Paul C. On the Relevancy of Modigliani and Miller to Banking: A Parable and Some Observations. Working Paper n. 93, Stanford University, 2010.

PINTO, Gustavo Mathias Alves. Regulação Sistêmica e Prudencial no Setor Bancário Brasileiro. Almedina Brasil, São Paulo, 2015.

PLANTIN, Guillaume; ROCHET, Jean-Charles. When Insurers go Bust: An economic analysis of the role and design of Prudential Regulation. Princeton University Press, Princeton, 2007.

PRATES, Daniela Magalhães; DE PAULA, Luiz Fernando. Capital account regulation in Brazil: An assessment of the 2009-2013 period. Brazilial Journal of Political Economy, vol. 37, n. 1. Centro de Economia Política, São Paulo, 2017, pgs. 108-129.

PRATES, Marcelo Madureira. Why Prudential regulation Will Fail to prevent Financial Crises. A Legal Approach. Working Papers 335. Banco Central do Brasil, Brasília, 2013.

RYAN, Peter J.; ZIEGLER, J. Nicholas. Patchwork Pacesetter: The United States in the Multilevel Process of Financial Market Regulation. capítulo em Negotiated Reform: The multilevel governance of financial regulation. Mayntz, Renate (ed.). Max Planck Institute for the Study of Societies, ed. Campus Verlag, 2015, pp. 65-96.

RUBIO, Margarida; CARRASCO-GALLEGO, José A. Macroprudential and monetary policies: Implications for financial stability and welfare. Journal of Banking \& Finance 49. Elsevier, Amsterdam, 2014, pgs 326-336.

RUBIO, Margarita; CARRASCO-GALLEGO, José A. The new financial regulation in Basel III and monetary policy: A macroprudential apporach. Journal of Financial Stability 26. Elsevier, Amsterdam, 2016, pgs 294-305.

STÂNGA, Irina M. Bank bailouts and bank-sovereign risk contagion channels. Journal of International Money and Finance 48. Elsevier, Amsterdam, 2014, pgs. 17-40. 
STREECK, Wolfgang. E Pluribus Unum? Varieties and Commonalities of Capitalism. MPIfG Discussion Paper 10/12. Max Planck Institute for the Study of Societies, Colônia, 2010.

STREECK, Wolfgang. How to Study Contemporary Capitalism? Archives of European Sociology, LIII, I. Cambridge University Press, Cambridge, 2012, pgs. 1-28.

. Taking capitalism seriously: towards na institutionalist approach to contemporary political economy. Socio-Economic Review 9. Oxford University Press, Oxford, 2011.

Buying Time: The Delayed Crisis of Democratic Capitalism.

Trad. Patrick Camiller. Verso, Segunda Edição, Edição Kindle, Nova York, 2017.

. The Politics of Public Debt: Neoliberalism, Capitalist Development, and the Restructuring of the State. MPIfG Discussion Paper 13/7, MaxPlanck-Institut für Gesellschaftsforschung, Köln; Max Planck Institute for the Study of Societies, Colônia, Julho 2013.

TEUBNER, Gunther. A Constitutional Moment? The Logics of 'Hit the Bottom'. Em KJAER, Poul; TEUBNER, Gunther (eds): The Financial Crisis in Constitutional Perspective: The Dark Side of Functional Differentiation. Hart, Oxford, 2011.

THANASSOULIS, John. Bank pay caps, bank risk, and macroprudential regulation. Journal of Banking \& Finance. Elsevier, Amsterdam, 2014, pgs. 139-151.

UEDA, Kenichi; VALENCIA, Fabián. Central bank Independence and macro-prudential regulation. Economic Letters. Elsevier, Amsterdam, 2017, pgs. 327-330.

VIOLA, Lora Anne. The Governance Shift: from Multilateral IGOs to Orchestrated Reform. capítulo em Negotiated Reform: The multilevel governance of financial regulation. Mayntz, Renate (ed.). Max Planck Institute for the Study of Societies, ed. Campus Verlag, 2015, pp. 17-36.

VIÑALS, Jose; FIECHTER, Jonathan et alii. The Making of Good Supervision: Learning to Say "No". IMF Position Staff Note SPN/10/08. International Monetary Fund, Washington D.C., 2010.

WEISS, Gregor N.F.; MÜHLNICKEL, Janina. Why do some insurers become systemically relevant? Journal of financial Stability 13. Elsevier, Amsterdam, 2014, pgs. 95-117. 
WILLIAMSON, Oliver. The Economic Institutions of Capitalism: Firms, Markets, Relational Contracting. Free Press, Nova York, 1985.

WOLF, Martin. Strip private banks of their power to create money. Financial Times, 24 de abril de 2014. 